\title{
Ignition characteristics of a temporally evolving $n$-heptane jet in an iso-octane/air stream under RCCI combustion-relevant conditions
}

\author{
Gwang Hyeon Yuª Minh Bau Luong ${ }^{\mathrm{b}}$, Suk Ho Chung ${ }^{\mathrm{b}}$, Chun Sang Yoo,** \\ ${ }^{a}$ Department of Mechanical Engineering, Ulsan National Institute of Science and Technology, Ulsan 44919, \\ Republic of Korea \\ ${ }^{b}$ Clean Combustion Research Center, King Abdullah University of Science and Technology, Thuwal, Saudi \\ Arabia
}

\begin{abstract}
The ignition characteristics of a temporally-evolving $n$-heptane jet in an iso-octane/air stream under reactivity controlled compression ignition (RCCI) combustion-relevant conditions are investigated using 2-D direct numerical simulations (DNSs) with a 116-species primary reference fuel $(\mathrm{PRF}) /$ air reduced mechanism. For the DNSs of RCCI combustion, iso-octane and $n$-heptane are chosen as two different fuels delivered by the port-fuel and direct-fuel injections, respectively. Therefore, the ignition characteristics of both fuels can be investigated by simulating the ignition of a temporally-evolving $n$-heptane jet with relative jet velocity, $U_{0}$, within iso-octane/air charge. It is found that the first-stage ignition kernels governed by the low-temperature chemistry first develop primarily within the $n$-heptane jet near the mixing layer regardless of $U_{0}$, and evolve into low-temperature flames, propagating into relatively fuel-rich mixtures in the $n$-heptane jet. High-temperature flames also develop first in the $n$-heptane jet, following the trajectories of low-temperature flames, and then, propagate towards both relatively fuel-lean mixtures of the iso-octane/air charge and fuel-rich mixtures of the $n$-heptane jet. They keep propagating into fuel-lean mixtures and finally end-gas auto-ignition occurs. It is also found that the first-stage ignition occurs more quickly with increasing $U_{0}$ due to enhanced mixing between relatively cold $n$-heptane jet and hot iso-octane/air charge, and consequently, the second-stage ignition also advances in time with increasing $U_{0}$, which are opposite to the results found in previous DNSs of RCCI combustion. Such ignition characteristics are more likely to prolong the overall combustion duration and reduce the peak of heat release rate with increasing $U_{0}$. In addition, chemical
\end{abstract}


explosive mode analysis (CEMA) identifies important variables and reactions for the low-, intermediate-, and high-temperature chemistries under such RCCI conditions.

Keywords: Keywords: Direct numerical simulation (DNS), reactivity-controlled compression ignition (RCCI), primary reference fuel (PRF), mixing layer, chemical explosive mode analysis (CEMA)

\section{Introduction}

Over the past two decades, numerous experimental and numerical studies have been performed for the development of novel internal combustion (IC) engines. As one of the next-generation IC engines, homogeneous-charge compression ignition (HCCI) engines have received great attention because they are able to significantly reduce pollutant emissions such as $\mathrm{NO}_{\mathrm{x}}$ and particulate matters by utilizing low-temperature combustion and to achieve high thermal efficiency with high compression ratio like diesel engine combustion [1-3]. Although HCCI engines have many advantages over the conventional IC engines, they still suffer from excessive pressure-rise rate (PRR) by simultaneous auto-ignition and ignition-timing control without explicit ignition sources. To resolve such drawbacks for the development of HCCI engines, several variants of HCCI engines have been proposed thus far, all of which adopt such strategies that temperature and/or composition inhomogeneities in the in-cylinder fuel/air charge are induced, leading to sequential ignition of the charge [1-14].

Among several variants of HCCI engines, a reactivity-controlled compression ignition (RCCI) engine has received considerable attention from the engine community since it can effectively control both the ignition timing and excessive PRR $[4-7,13,15,16]$. RCCI engines are generally designed to use two fuels with different auto-ignition characteristics: one is lowreactivity fuel (e.g., gasoline, ethanol, and iso-octane) from which most heat is released and the other is high-reactivity fuel (e.g., diesel, dimethyl ether (DME), and n-heptane) that serves as an ignition promotor to initiate overall combustion process. The high-reactivity

\footnotetext{
*Corresponding author.

Email address: csyoo@unist.ac.kr (Chun Sang Yoo)
} 
fuel is directly injected into the low-reactivity fuel/air charge already supplied through the port injection, and hence, a mixing layer cannot help but develop between two fuel streams, which can affect the overall characteristics of the RCCI combustion.

Regarding the mixing layer effects on the ignition characteristics of fuel/air mixtures, many numerical studies have been performed by several different research groups. Im et al. [17] elucidated the ignition characteristics of a hydrogen/air scalar mixing layer in homogeneous turbulence. They found that under weak to moderate turbulence conditions, the overall ignition is promoted by turbulence because it enhances the mixing between fuel and oxidizer. Under strong turbulence condition, however, the overall ignition is retarded mainly due to temperature/radical dissipation by high turbulence, for which its timescale is much shorter than the ignition delay of the mixture.

Mastorakos and co-workers [18-22] investigated the fundamental ignition characteristics in turbulent single- and two-phase flows. Especially, Borghesi et al. [21] performed DNSs of turbulent $n$-heptane spray auto-ignition under high pressure and intermediate temperature condition and found that initial turbulence is more likely to reduce the overall ignition delay because it promotes the mixing between fuel and air streams. Recently, Demosthenous et al. [22] investigated the mixing layer effect on premixed methane/air flame initiated by $n$ heptane spray auto-ignition. They found that the amount of $n$-heptane injection can affect the ignition characteristics of methane/air charge: for a case with relatively-large amount of $n$-heptane injection, methane/air mixture is primarily consumed by auto-ignition; however, for relatively-small amount of fuel injection, methane oxidation occurs by typical deflagration mode of combustion.

More recently, Jin et al. [23] investigate the ignition and flame characteristics in turbulent pilot ignited DME/methane-air mixing layer under diesel engine-relevant condition. They showed that the triple flame palys an important role during the flame development. And also, the cool flame and propagation of triple flames are identified. Krisman et al. [24, 25] studied the importance of the mixing layer effects on the ignition characteristics of dimethyl-ether (DME) under diesel engine-relevant conditions by using 2-D DNS. They found that low-temperature chemistry (LTC) occurs at fuel-lean mixtures in the mixing 
layer, which consequently affects high-temperature chemistry (HTC) and hence, the overall ignition occurs by a multi-staged and multi-mode process. Borghesi et al. [26] investigated the low-temperature reaction effects on the ignition characteristics of temporally evolving air $/ n$-dodecane jet at low-temperature diesel-relevant conditions by using 3 -D DNS. They found that low-temperature reactions promote high-temperature reactions. Hence, the hightemperature ignition is faster than homogeneous ignition. Luong et al. $[15,16]$ investigated the ignition characteristics of RCCI combustion in homogeneous turbulence by performing 2D DNSs and figured out that fuel-reactivity stratification in the in-cylinder charge has more significant effect on the overall RCCI combustion within the negative temperature coefficient (NTC) regime, which is further elucidated by the chemical explosive mode analysis (CEMA) identifying the important variables and reactions for the RCCI combustion. In these studies, it was assumed that the injection of both low- and high-reactivity fuels is finished prior to the start of simulations, and as such, only the effects of homogeneous turbulence on the RCCI combustion were elucidated. As mentioned above, however, the high-reactivity fuel is directly injected to the low-reactivity fuel/air charge, and hence, a mixing layer that can affect the overall ignition characteristics develops between the two streams.

From an experimental point of view, the mixing layer effect can be interpreted as that of the pressure of direct-fuel injection, $p_{\text {inj }}$, which is directly related to the fuel-jet velocity. From many previous experimental studies [27-29], it was found that the overall combustion timing is advanced in time with increasing $p_{\text {inj }}$ due to enhanced fuel-air mixing. Moreover, thermal efficiency is also increased with $p_{\text {inj }}$ while pollutant emissions including CO, unburned hydrocarbon (UHC), and $\mathrm{NO}_{\mathrm{x}}$ are reduced. Although the effects of $p_{\text {inj }}$ on the overall combustion characteristics have been elucidated from experimental studies, there is no detailed analysis on the effects of the mixing layer velocity on HCCI-typed combustion.

Therefore, the objective of this study is to investigate the fundamental ignition characteristics of a temporally-evolving $n$-heptane jet within an iso-octane/air charge by performing 2-D DNSs, which is an idealized configuration for RCCI combustion. The effect of the mixing layer between the $n$-heptane jet and iso-octane/air charge is elucidated by varying the relative jet velocity, $U_{0}$. Then, it is further appreciated by comparing the results with those 
in homogeneous turbulence without a mixing layer. The chemical aspects of the ignition under these conditions are also elucidated by applying CEMA to DNS data and by evaluating its explosive and participation indices [30-32].

\section{Numerical methods and initial conditions}

The Sandia DNS code, S3D, was used to solve the compressible Navier-Stokes, species continuity, and total energy equations [33]. S3D is linked with CHEMKIN and TRANSPORT software libraries $[34,35]$ to evaluate reaction rates, and thermodynamic and mixtureaveraged transport properties. A fourth-order explicit Runge-Kutta method [36] and an eighth-order central difference scheme [37] are employed for time integration and spatial derivatives, respectively. A tenth-order filter is also applied to eliminate any spurious highfrequency fluctuations in the solution [37] while the stiffness removal technique is adopted to remove any chemical timescales shorter than 10 ns [38]. For more details of the numerical methods, readers are referred to [33].

To account for the compression heating and expansion cooling effects by the piston motion in an engine cylinder, we adopt a compression heating model recently developed by Bhagatwala et al. [13] and then modified by Luong et al. [14]. Based on the cylinder volume of an IC engine represented by the slider-crank relation [39], the motored pressure trace close to top dead center (TDC) can be determined by:

$$
P_{\mathrm{m}}(t)=P_{0, \mathrm{~m}}\left[1+g^{2} \pi^{2} \frac{\left(t-t_{0}\right)^{2}}{t_{c}^{2}}\right]^{-n},
$$

where $P_{0, \mathrm{~m}}$ is the motored TDC pressure, $t_{c}$ is the time taken for one crank rotation, $t_{0}$ is the time at the TDC and $g$ is a model factor to account for the crank slider geometry. The experimental pressure trace from Wissink et al. [40] is used to calibrate the geometry factor in Eq. 1. Relevant engine parameters taken from [40] are listed in Table 1.

To incorporate the pressure change by the piston motion into DNSs, a mass source term together with the corresponding momentum and energy source terms are included in the 
governing equations as in $[13,14]$. Figure 1 shows the modeled motored-pressure trace that matches the experimental one without any noticeable discrepancies. For more details of the physical models and relevant engine conditions, readers are referred to [14].

All 2-D DNSs start at $-25^{\circ} \mathrm{CA}$ ATDC at which the injections of $i s o$-octane and $n$-heptane are already finished. Based on the motored pressure trace with an intake pressure of $1 \mathrm{~atm}$, the initial mean pressure, $P_{0}$, initial mean temperature, $T_{0}$, and the mean equivalence ratio, $\phi_{0}$, are set to be $18.2 \mathrm{~atm}, 720 \mathrm{~K}$, and 0.45 , respectively. The average fuel is PRF50. To mimic the process of two fuel injections in the RCCI combustion, a lean iso-octane/air charge supplied by the port injection is assumed to be homogeneously distributed through the computational domain while an $n$-heptane jet by the direct injection is superimposed on the iso-octane/air charge. The $n$-heptane jet is assumed to move with a relative-velocity, $U_{0}$, in the middle of the domain and two mixing layers develop between the two fuel streams, consequently inducing inhomogeneities in the composition and temperature fields. Figure 2 shows a schematic of the initial conditions for DNSs. The relative velocity, temperature, and species composition of the $n$-heptane jet are specified by a top-hat shaped profile function as in $[24,25]$ :

$$
f(y)=\frac{1}{2}\left[\tanh \left(\left(y-\frac{2}{5} H\right) / \sigma\right)-\tanh \left(\left(y-\frac{3}{5} H\right) / \sigma\right)\right]
$$

where $H$ is the $y$-directional domain length and $\sigma$ is the initial mixing layer thickness. For the present DNSs, the mixing layer thickness of $50 \mu \mathrm{m}$ is chosen not to induce a finer grid resolution than the current resolution of $1.25 \mu \mathrm{m}$.

It was reported from Wang and Rutland [41] that at the end of the evaporation process of $n$-heptane fuel spray in turbulent flow, local temperature is inversely proportional to local equivalence ratio, $\phi$, due to the evaporative cooling effect of the fuel spray and consequently, the maximum temperature difference in the engine cylinder is approximately $100 \mathrm{~K}$, which is consistent with recent experimental results [1, 7, 42, 43]. In addition, Dec and Hwang [4] experimentally found that thermal stratification level in an HCCI engine is approximately 
$T^{\prime}=13.3 \mathrm{~K}$; Tang et al. [44] also found that in the presence of fuel stratification produced by the direct-fuel injection, the range of $\phi$ is approximately $0.2 \sim 2.0$. Based on previous experimental results, the mean temperatures of $i s o$-octane/air stream and $n$-heptane jet are set to be 740 and $650 \mathrm{~K}$, respectively. Temperature and concentration fluctuation RMS, $T_{\text {hep }}^{\prime}$ and $\phi_{\text {hep }}^{\prime}$, are also set to be $20 \mathrm{~K}$ and 0.4 , respectively. To account for the evaporative cooling of the directly-injected fuel, we also assumed negatively-correlated (NC) $T-\phi$ distribution in the $n$-heptane jet. As such, the distributions of $T$ and $\phi$ lie within an optimal range for RCCI combustion to maintain low-temperature combustion with ultra-low emissions [7, 42, 45]. Note that in RCCI combustion, the injection of high reactivity fuel is typically completed prior to $-60 \sim-40{ }^{\circ} \mathrm{CA}$ ATDC, and hence, we assume that the evaporation of $n$-heptane jet is already finished at the beginning of DNSs and its effect is incorporated in the low mean temperature and the high mean equivalence ratio of the $n$-heptane jet. Figure 3 shows the initial distributions of $n$-heptane, iso-octane, $\phi$, and PRF for Cases 1-3.

As in $[8,12,14,24,25,46,47]$, the initial turbulent flow field on the iso-octane/air charge is generated using the isotropic kinetic energy spectrum function by Passot-Pouquet [48], which is also used to prescribe the initial temperature and concentration fields with different random numbers. The most energetic length scales of turbulence, temperature, and concentration, $l_{e}, l_{T e}$, and $l_{m e}$ are set to $1.2 \mathrm{~mm}$ for all DNSs. Similar to previous studies $[8,9,14,47]$, the turbulence intensity, $u^{\prime}$, of $0.4 \mathrm{~m} / \mathrm{s}$ is selected such that the turbulence time scale, $\tau_{t}=l_{e} / u^{\prime}$, of $3.0 \mathrm{~ms}$, is similar to $\tau_{\mathrm{ig}}^{0}$ in a real HCCI engine. In real HCCI engines, ignition delay is approximately $2 \mathrm{~ms}$ and turbulence timescale is comparable to the ignition delay $\sim O(1) \mathrm{ms}[46,49,50]$. Note that even though turbulence intensity of the n-heptane jet can vary depending on its mean velocity, we do not consider different $u^{\prime}$ for different $U_{0}$. For relatively-low Reynolds number n-heptane jets $\left(\operatorname{Re}_{\mathrm{j}}<1000\right)$, their turbulence intensities are supposed to be low (e.g. $1 \sim 5 \%$ of the mean velocity). Since the current turbulence intensity of $u^{\prime}=0.4 \mathrm{~m} / \mathrm{s}$ is quite comparable to those of 5 and $10 \mathrm{~m} / \mathrm{s}$ turbulent jets, we believe that the current DNS results would not change much with different $u^{\prime}$ for different cases. Also note that 2-D turbulence without vortex stretching and tilting is qualitatively different from 3-D turbulence. It is, however, still valuable to investigate 
HCCI-typed combustion with 2-D turbulence because the overall combustion characteristics of 2-D DNSs are not very different from those of 3-D DNSs [51-55]. For a parametric DNS study, therefore, it is more feasible to conduct 2-D DNSs than extremely-expensive 3-D DNSs.

A 2-D DNS domain of $3.2 \times 3.2 \mathrm{~mm}^{2}$ discretized with 2560 grids points in each direction is used for all 2-D DNSs. Such a fine grid resolution of $1.25 \mu \mathrm{m}$ with a time step of $2.5 \mathrm{~ns}$ is required to resolve thin flame fronts. A 116-species PRF/air reduced mechanism for PRF oxidation [10] is used and the periodic boundary conditions are applied to all boundaries. To investigate the effect of the relative velocity between the two fuel/air charge, three different cases were simulated by varying $U_{0}$ : from Cases 1 to $3, U_{0}=0,5$, and $10 \mathrm{~m} / \mathrm{s}$, respectively. The 2-D DNSs were performed on a Cray XC40 system at King Abdullah University of Science and Technology. Each of the DNSs required approximately 1.0 million CPU hours.

\section{Overall ignition characteristics}

Figure 4 shows the temporal evolution of the mean pressure, $\bar{P}$, and heat release rate (HRR), $\overline{\dot{q}}$, for Cases 1-3 together with those of the corresponding 0-D ignition representing an ideal HCCI combustion. The time is normalized by the $0-\mathrm{D}$ ignition delay, $\tau_{\mathrm{ig}}^{0}$, of $2.77 \mathrm{~ms}$ of the PRF50/air mixture. Prior to the detailed analysis of the overall ignition characteristics, it should be noted that from previous DNS studies of RCCI combustion $[15,16]$ without an $n$-heptane jet, turbulence with large $u^{\prime}$ and short $\tau_{t}$ is found to effectively homogenize the initial mixture, and hence, the first- and second-stage ignitions are retarded with increasing $u^{\prime}$ while the peak $\overline{\dot{q}}$ of the first stage ignition is decreased and that of the second-stage ignition is increased.

Several points are noted from Fig. 4. First, the first-stage ignition is advanced in time and the corresponding peak $\bar{q}$ is increased with increasing $U_{0}$ even though their first-stage ignitions occur later than that of the 0-D ignition. Second, the start of the second-stage ignition is advanced in time and the duration of heat release is also increased with increasing $U_{0}$. Third, it is also readily observed that there exists a third peak of $\overline{\dot{q}}$ for Cases 1 and 2 with relatively-low $U_{0}$. Especially for Case 1, the third peak occurs later than the 0-D ignition of 
PRF50/air mixture. However, the peak $\bar{q}$ of the second-stage ignition shows non-monotonic behavior with increasing $U_{0}$. These results are somewhat counterintuitive considering the previous DNS results that the overall ignition is delayed with increasing $u^{\prime}[13,15,16]$. As mentioned above, however, it is found from previous experiments that the overall ignition of RCCI combustion can be advanced in time with increasing fuel injection pressure [2729]. Since high fuel injection pressure in experiments corresponds to large $n$-heptane jet velocity, $U_{0}$, in the present simulations, it can be conjectured that the above overall ignition characteristics are primarily attributed to those of the $n$-heptane jet with different $U_{0}$.

To understand the above overall ignition characteristics of the $n$-heptane jet in the $i s o-$ octane stream, we identify the contribution of each fuel stream to the mean HRR as shown in Fig. 5. For this purpose, we adopt a mixture fraction, $\xi$, which is evaluated based on the nitrogen mass fraction, $Y_{\mathrm{N}_{2}}$, ranging from zero in the iso-octane stream to unity in the $n$-heptane jet as in [22]:

$$
\xi=\frac{Y_{\mathrm{N}_{2}}-Y_{\mathrm{N}_{2}}^{\text {oct }}}{Y_{\mathrm{N}_{2}}^{\text {hep }}-Y_{\mathrm{N}_{2}}^{\text {oct }}},
$$

where the superscripts 'oct' and 'hep' represent the iso-octane stream and the $n$-heptane jet, respectively. Due to the stratification in the $n$-heptane jet, local $\xi$ can be much less than unity within the mixing layer. For the present study, $\xi=0.1$ is chosen as a threshold value that can effectively enclose the $n$-heptane jet while clearly distinguishing two streams. Therefore, it is assumed that heat is released from the n-heptane jet if $\xi>0.1$; otherwise, it is determined to originate from the iso-octane stream. Note that since the mixing layer thickness is much narrower than the domain size, heat released from each stream does not change much with different threshold values of $\xi$.

Several points are to be noted from Fig. 5. First, almost all of heat is released from the $n$-heptane jet during the first-stage ignition, and as such, we can confirm that the first-stage ignition of the system is primarily governed by the ignition characteristics of the $n$-heptane jet. In general, the advanced first-stage ignition is more apt to accelerate the second-stage 
ignition and consequently advance in time the overall combustion in HCCI-typed engines $[8,9,11,12]$. Similarly, we can identify that the second-stage ignition in the $n$-heptane jet starts faster and the overall heat release is more distributed over time with increasing $U_{0}$ due to the advanced first-stage ignition and subsequent ignition characteristics. Second, it is also readily observed that while the overall ignition of the $n$-heptane jet exhibits typical twostage ignition characteristics of high hydrocarbon fuel/air mixtures under high pressures, the iso-octane/air stream shows unusual ignition characteristics featuring two peaks of the mean HRR, especially for cases with relatively-low $U_{0}$. Since iso-octane/air mixture usually shows one-stage ignition characteristics even at high pressures [11], and thus, we can conjecture that the unusual ignition characteristics of the iso-octane/air stream are related to the ignition of $n$-heptane jet and the mixing between the two streams.

We identify these overall ignition characteristics of the present RCCI combustion by examining the instantaneous snapshots of the HRR field at several different times for Cases 1-3 as shown in Fig. 6 . The local HRR is normalized by $\dot{q}=50 \mathrm{~J} / \mathrm{mm}^{3}$ s to simultaneously show low- and high-temperature flames and the white solid lines represent the $\xi=0.1$ isoline. It is readily observed that the first-stage HRR (see the second column) and the most of the second-stage HRR (see the fourth column) occur in the $n$-heptane jet for all cases. Meanwhile, iso-octane/air mixtures outside of the $n$-heptane jet start to participate in heat generation after the $n$-heptane jet is almost consumed.

More specifically, during the early phase of the first-stage ignition (see the first column), several low-temperature ignition kernels develop near the mixing layer in the $n$-heptane jet at which the scalar dissipation rate, $\chi$, is very low (not shown here), similar to previous studies $[25,44]$. Note that $\chi$ is defined by $\chi=2 D|\nabla \xi|^{2}$, where $D$ is the thermal diffusivity of local mixture. At a later time (see the second column), more low-temperature ignition kernels develop and merge with one another, leading to low-temperature flames propagating into fuel-rich mixtures inside of the $n$-heptane jet until high-temperature combustion occurs. At the time of the third column, the second-stage ignition kernels start to develop and evolve into high-temperature flames following the trajectories of low-temperature flames at mixtures for which $\xi$ is much greater than that of low-temperature ignition kernels in the $n$-heptane 
jet. At the second-stage ignition (see the fourth column), the high-temperature flames keep consuming the remaining $n$-heptane jet, leading to the maximum $\overline{\dot{q}}$. After the consumption of the $n$-heptane jet is almost finished, they propagate into fuel-lean mixtures in the isooctane/air stream (see the fifth column). After that, the remaining iso-octane/air mixtures auto-ignite simultaneously, similar to the end-gas auto-ignition of the HCCI combustion. The end-gas auto-ignition in Cases 1 and 2 is primarily attributed to the third peak of $\bar{q}$ in Fig. 4a.

In the present DNSs, large $U_{0}$ is more apt to enhance the mixing of the relativelyhot iso-octane/air stream and relatively-cold $n$-heptane jet, leading to local temperature increase of the $n$-heptane jet in the mixing layer (see the first-stage ignition in Fig. $5 \mathrm{c}$ ). The shear mixing between the two streams eventually advances the first-stage ignition in the $n$-heptane jet and enhances the development of high-temperature flames. Once such high-temperature flames develop, large $U_{0}$ or large $u^{\prime}$ is more apt to increase the flame area by stretching the flames as shown in Fig. 6, which consequently advances the second-stage ignition and prolongs the combustion duration. These results are quite similar to those of HCCI combustion with large $T^{\prime}[47,56]$ and SACI combustion [9].

Also note that the current first-stage HRR is relatively small compared to that of the main combustion due to the temperature range of the n-heptane jet determined from experiments (see Figs. 4 and 5). However, if the mean temperature of the $n$-heptane jet becomes lower, the intensity of the first-stage ignition would be larger while its delay time is increased, which subsequently retards the second-stage (or main) ignition in time. In such situation, high $U_{0}$ enhances the mixing between the two streams and consequently, the overall combustion would become more like HCCI combustion rather than RCCI combustion and the effect of $U_{0}$ might become opposite to that of the present DNSs.

To further elucidate the effects of the $n$-heptane jet on the ignition, the scatter plots of temperature, HRR, and $n$-heptane mass fraction as a function of the mixture fraction for Cases 1 and 3 are shown in Figs. 7 and 8. It is readily observed from the figures that at the very beginning $\left(t / \tau_{\text {ig }}^{0} \sim 0.036\right)$, temperature is inversely proportional to the mixture fraction due to the initial negatively-correlated $T-\phi$ distribution in the $n$-heptane jet and the 
temperature distributions for both cases are nearly identical. In addition, $n$-heptane mass fraction is proportional to the mixture fraction. At a later time $\left(t / \tau_{\mathrm{ig}}^{0} \sim 0.677\right.$ and 0.634$)$, however, the range of temperature distribution and heat release distribution and $n$-heptane mass fraction in the mixture fraction space for Case $3(0.2<\xi<0.8)$ is much narrower than that for Case $1(0.2<\xi<1.0)$. Moreover, this trend keeps continuing till the end of combustion for both cases and the mixture fraction space for Case 3 is shrunken. These results are primarily attributed to strong shear mixing between the two streams by large $U_{0}$ in Case 3 compared to homogeneous turbulence mixing by small $u^{\prime}$ in Case 1 . The mean HRR is nearly zero prior to the first-stage ignition, and hence, the temperature increase in the $n$-heptane stream at relatively-large $\xi$ is primarily attributed to the effect of turbulence not heat release. As explained above, this strong mixing by large $U_{0}$ enhances the first-stage ignition for Case 3.

For Case 1, the second-stage ignition occurs over a broad range of $0.2<\xi<1.0$ while for Case 3, it occurs over a relatively-narrow range of $0.06<\xi<0.42$. Moreover, most $n$ heptane is consumed during the second-stage ignition for Case 3 while a considerable amount of $n$-heptane still remains unburned for Case 1 even after the second-stage ignition. Since turbulence intensity for Case 1 is relatively low, the $n$-heptane jet remains without mixing with the iso-octane/air stream till the end of combustion as shown in Fig. 6. Therefore, the whole $n$-heptane jet is consumed sequentially from the mixing layer to the center of the jet during the combustion process. For Case 3, however, high turbulence induced by large $U_{0}$ breaks up the $n$-heptane jet into several small parts as shown in Figs. 6 and 8 . Consequently, these small pockets of $n$-heptane are sequentially consumed, prolonging the combustion duration for Case 3.

From the present results together with previous experimental and numerical results [914, 27-29, 47, 56], we conjecture that both the excessive PRR and the ignition timing can be controlled not only by the degree of temperature, composition, and reactivity fluctuations in fuel/air charge but also by fuel injection timing and pressure to induce appropriate mixing layers between high reactivity fuel stream and low reactivity fuel/air stream. 


\section{Combustion mode analysis}

From previous numerical and experimental studies $[1,3,5,8]$, it was found that as the level of temperature inhomogeneity, $T^{\prime}$, in fuel/air mixture increases, the overall combustion is more likely to occur by the deflagration mode of combustion, which consequently reduces the peak HRR and prolongs the combustion duration. In addition, the high level of mixture inhomogeneity also leads to enhancing the deflagration mode of combustion [12]. To investigate the effect of the $n$-heptane jet on the combustion mode, we perform the Damköhler number analysis that can quantitatively measure the occurrence of deflagration and spontaneous ignition modes during the combustion. The Damköhler number is defined as $[8,46,49,56-58]$ :

$$
D a=\frac{\dot{\omega}_{k}}{\left|-\nabla \cdot\left(\rho Y_{k} \mathbf{V}_{k}\right)\right|},
$$

where $Y_{k}, \mathbf{V}_{k}$, and $\dot{\omega}_{k}$ denote the mass fraction, diffusion velocity, and net production rate of species $k$, respectively. $Y_{c} \equiv Y_{\mathrm{CO}_{2}}+Y_{\mathrm{CO}}$ is used for the Damköhler number analysis. As in previous studies $[8,11,12,14,46], D a$ values in the diffusive limit for $n$-heptane jet and iso-octane/air stream are found to be approximately 2.3 and 1.0, respectively. These values are obtained through a series of 1-D laminar simulations of which initial conditions are the same as those of the 2-D DNSs. As such, local combustion is determined to occur by the deflagration mode when its $D a$ is less than 2.3 and 1.0 , respectively. Note that the diffusive limit represents deflagration wave propagation in a highly-reactive mixture without auto-ignition $[8,9,14,46,47,59]$.

Figure 9 shows the temporal evolutions of the fraction of HRR from the deflagration mode and the mean HRR in the $n$-heptane jet and the iso-octane/air stream for Cases 1-3. During the first-stage ignition, slightly less than half of $\dot{q}$ occurs by the deflagration mode in the $n$-heptane jet for all cases while heat is rarely released from the $i$ so-octane/air stream.

During the second-stage ignition, most of $\dot{q}$ occurs by the deflagration mode in the $n$ heptane jet for all cases while approximately half of $\dot{q}$ occurs by the deflagration mode in 
the iso-octane/air stream. However, for Case $3, \dot{q}$ in the iso-octane/air stream is quite comparable to that in the $n$-heptane jet during the second-ignition stage while it is quite small for Cases 1 and 2. As such, the third-ignition stage is rarely shown in Case 3 due to this simultaneous heat release in both streams during the second-stage ignition. For Cases 1 and 2, however, heat release occurs by the spontaneous ignition mode during the third-stage ignition in the form of the end-gas auto-ignition. Due to the characteristics of heat release from the deflagration mode for Cases $1-3$, the total heat release from the deflagration mode is approximately $73 \%$ for Case 1 while those for Cases 2 and 3 are approximately $67 \%$. Since the combustion duration for Case 1 is longer than those for Cases 2 and 3, we can expect more heat release from the deflagration mode for Case 1.

To further identify the characteristics of the combustion waves in Case 1, the transport budget analysis is performed by comparing the relative magnitudes of reaction and diffusion terms of a species equation $[13,51,52,59-61]$. For the analysis, $\mathrm{CH}_{2} \mathrm{O}$ and $\mathrm{CO}$ are selected because they are the most important species in the low- and high-temperature chemistries, respectively [16]. Figures 10 shows the isocontours of the normalized HRR and transport budget terms of $\mathrm{CH}_{2} \mathrm{O}$ and $\mathrm{CO}$ together with the scalar dissipation rate at the first-, secondand third-stage ignitions for Case 1. As shown in Fig. 10a and b, the reaction and diffusion terms are comparable at the combustion waves during the first- and second-stage ignitions although the diffusion term is smaller than the corresponding reaction term. As explained above, in the diffusive limit $[8,11,12,14,46]$, the diffusion term is relatively small compared to the reaction term because mixture upstream of the flame front is already highly reactive due to high-temperature and pressure $[8,9,47]$. As such, the combustion waves in Fig. 10a and $\mathrm{b}$ are deflagration waves rather than spontaneous ignition waves. In addition, relativelyhigh scalar dissipation rate is also observed at the deflagration waves, which indicates that the deflagration waves develop along the mixing layer between the two streams. At the third-stage ignition (see Fig. 10c), however, the reaction term is significantly larger than the diffusion term upstream of the reaction front, which indicates that the combustion occurs by spontaneous ignition mode in the form of the end-gas auto-ignition.

Figure 11 shows the result of the transport budget analysis at three different times for 
Case 3. It is readily observed from Fig. 11a and b that the combustion waves are highly stretched and curled by strong vortices induced by high $U_{0}$, and hence, the combustion wave structures become more complicated than those in Case 1. However, the characteristics of the combustion waves are quite similar to those in Case 1: the diffusion terms are comparable to the diffusion terms especially at the first- and second-stage ignition, which implies that they are deflagration waves in the diffusive limit. At the final stage of combustion (Fig. 11c), the reaction term is significantly larger than the diffusion term at Line $\mathrm{C}$ as in Case 1, which indicates that the combustion occurs by spontaneous ignition mode in the form of the endgas auto-ignition although the autoignition area and the amount of HRR from it are much smaller than those of Case 1.

\section{Chemical explosive mode analysis (CEMA)}

In this section, the chemical explosive mode analysis (CEMA) is adopted to identify the spatial ignition characteristics of the $n$-heptane jet in the lean iso-octane/air stream relevant to the RCCI engine condition as in previous DNS studies of HCCI-type combustion $[8,10,11,15,47]$ and laminar/turbulent lifted jet flames in autoignitive conditions [56, 58, 59]. The CEMA is briefly explained here and for more details of it, readers are referred to [30-32]. The Jacobian of the chemical source term, $\mathbf{J}_{\omega}$, of a discretized governing equation of a reacting flow retains the chemical information of local mixture. Therefore, we can use $\mathbf{J}_{\omega}$ to determine the chemical characteristics of local mixtures. For this purpose, we define a chemical mode as an eigenmode of $\mathbf{J}_{\omega}$, which is associated with an eigenvalue, $\lambda_{e}$, and a corresponding pair of the left and right eigenvectors, $\mathbf{b}_{e}$ and $\mathbf{a}_{e}$. A chemical mode, for which the real part of eigenvalue is positive (i.e. $\operatorname{Re}\left(\lambda_{e}\right)>0$ ), is defined as a chemical explosive mode (CEM). Since local mixture with a CEM can auto-ignite if there are no thermal and radical losses, a CEM indicates an intrinsic chemical feature of ignitable mixture.

The contribution of each variable and reaction to a CEM can be quantified by evaluating explosive index, EI, of each variable and participation index, PI, of each reaction, which can identify critical chemical kinetic processes during the ignition. They are defined as [31, 32]: 


$$
\begin{gathered}
\mathbf{E I}=\frac{\left|\mathbf{a}_{e} \otimes \mathbf{b}_{e}^{\mathrm{T}}\right|}{\sum\left|\mathbf{a}_{e} \otimes \mathbf{b}_{e}^{\mathrm{T}}\right|}, \\
\mathbf{P I}=\frac{\left|\left(\mathbf{b}_{e} \cdot \mathbf{S}\right) \otimes \mathbf{R}\right|}{\sum\left|\left(\mathbf{b}_{e} \cdot \mathbf{S}\right) \otimes \mathbf{R}\right|},
\end{gathered}
$$

where $\mathbf{S}$ and $\mathbf{R}$ represent the stoichiometric coefficient matrix and the vector of the net rates for reactions, respectively. The symbol $\otimes$ represents the element-wise multiplication of two vectors. EI and PI indicate the normalized contribution of each variable and reaction to the CEM, respectively, and hence, controlling species and reactions for the ignition of the $n$-heptane jet in the iso-octane/air stream can be elucidated by evaluating their values.

To estimate the contribution of the low-, intermediate-, and high-temperature chemistries (LTC, ITC, and HTC) of the $n$-heptane and iso-octane oxidations to the overall combustion, we evaluate the conditional means of EI and PI of important variables and reactions. Figure 12 shows the conditional means of HRR, EI and PI given temperature and mixture fraction for Case 1 at the first-stage ignition, $t / \tau_{i g}^{0}=0.667$.

Several points are noted from Fig. 12. First, it is readily observed from the figure that most of heat is released from the $n$-heptane jet with $810 \mathrm{~K}<T<860 \mathrm{~K}$ and $\xi>0.1$ in the vicinity of the iso-octane/air stream (see Fig. 6) even though relatively-small amount of heat is released from the $i s o$-octane/air stream with $\xi<0.1$. Second, temperature is identified as the most important variable to the CEM for the most temperature and mixture fraction ranges. However, $\mathrm{RO}_{2}, \mathrm{O}_{2} \mathrm{QOOH}$, and $\mathrm{KOOH}$ are found to be important within the core $n$-heptane jet with $T<810 \mathrm{~K}$ and $\xi>0.8$ (see Figs. 12a and c) where the low-temperature chemistry of the $n$-heptane oxidation (e.g., $\mathrm{RO}_{2}$ isomerization (R645-R651), chain branching reactions of $\mathrm{KOOH} \mathrm{(R669,} \mathrm{R786-R791),} \mathrm{and} \mathrm{H-atom} \mathrm{abstraction} \mathrm{of} n$-heptane; (R546-R561) see Figs. 12b and d) is still underway. In addition, $\mathrm{HO}_{2}$ and $\mathrm{H}_{2} \mathrm{O}_{2}$ are found to be important variables to the CEM for mixtures with intermediate temperature in the iso-octane/air stream $(860 \mathrm{~K}<T<880 \mathrm{~K}$ and $\xi<0.05$; see Fig. 12a and $\mathrm{c})$. This is because the initiation reactions of iso-octane featured by $\mathrm{RH}+\mathrm{O}_{2} \rightarrow \mathrm{R}+\mathrm{H}_{2} \mathrm{O}$ ( $\mathrm{R} 813-\mathrm{R} 815$; not shown 
here) becomes important at iso-octane/air stream where iso-octane decomposition reactions (R734-R738, R792-R794) become dominant. Then, the $\mathrm{H}$ atom abstraction reactions of isooctane featured by $\mathrm{RH}+\left(\mathrm{OH}, \mathrm{HO}_{2}, \mathrm{RO}\right) \rightarrow \mathrm{R}+\left(\mathrm{H}_{2} \mathrm{O}, \mathrm{H}_{2} \mathrm{O}_{2}, \mathrm{ROH}\right)(\mathrm{R} 739-\mathrm{R} 741, \mathrm{R} 759-\mathrm{R} 803$, R807-R809) becomes important at the near $n$-heptane jet $(0.005<\xi<0.1$; see Fig. 6$)$. These results indicate that the first-stage ignition of Case 1 is determined by the first-stage ignition of the $n$-heptane jet and the evolution of cool flames from the first-stage ignition kernels.

Figure 13 shows the conditional means of EI of important variables and PI of reactions together with the HRR at the second-stage ignition $\left(t / \tau_{i g}^{0}=0.825\right)$. It is readily observed that most of heat is released from high-temperature $n$-heptane jet $(T>1500 \mathrm{~K}$ and $\xi>$ 0.2), where the HTC represented by CO oxidation (R24) and hydrogen chemistry (R1, R9, and $\mathrm{R} 13$ ) is found to be predominant. In this region, temperature, $\mathrm{CO}$, and $\mathrm{OH}$ are also identified as the most important variables to the CEM. At the region with $T<1500 \mathrm{~K}$, however, the ITC represented by QOOH decomposition (R655-R662, R652-R654) and $\mathrm{H}_{2} \mathrm{O}_{2}$ decomposition (R16) is found to be dominant. It is of interest to note that heat is rarely released within the iso-octane/air stream $(\xi<0.1)$, which indicates that the second-stage ignition of Case 1 is also governed by the $n$-heptane oxidation and the iso-octane/air mixture is consumed by the end-gas auto-ignition.

Figures 14 and 15 show the conditional means of HRR, EI of important variables, and PI of critical reactions given temperature and mixture fraction for Case 3 at the first-stage ignition, $t / \tau_{i g}^{0}=0.635$, and the second-stage ignition, $t / \tau_{i g}^{0}=0.841$, respectively. It is of importance to note that all the CEMA results of Case 3 are nearly identical to that of Cases 1, and even to previous CEMA results of RCCI/SCCI combustion with different flow configurations [15], implying that the sequence of LTC, ITC, and HTC occurrence does not change much with different flow configuration. However, a slight change in flow and mixture composition can lead to significantly different RCCI combustion behavior. 


\section{Conclusions}

The ignition characteristics of a lean PRF/air mixture with a $n$-heptane stream under RCCI condition were investigated by using 2-D DNSs with a 116-species PRF reduced mechanism. A parametric study was performed by varying the mixing layer velocity, $U_{0}$, with a compression heating model to account for the compression heating and expansion cooling effects of the piston motion in an engine cylinder. It was found that low-temperature ignition kernels develop in the $n$-heptane jet within the mixing layer and evolve into the low-temperature flames, propagating into relatively fuel-rich mixtures. At a later time, high-temperature flames develop at fuel-rich mixtures in the $n$-heptane jet, following the trajectories of low-temperature flames. After the consumption of the $n$-heptane jet is nearly finished, they start to move into the iso-octane/air stream. Finally, an end-gas auto-ignition occurs at the iso-octane/air stream. It was also found that the first-stage ignition is advanced in time and the peak of $\overline{\dot{q}}$ is increased with increasing $U_{0}$, ultimately enhancing the secondstage ignition. This is because large $U_{0}$ enhances the mixing of the relatively-cold $n$-heptane jet with the relatively-hot iso-octane/air stream, and as such, the first-stage ignition is advanced in the $n$-heptane jet. Consequently, the second-stage ignition is also advanced and the peak of $\overline{\dot{q}}$ is decreased while combustion duration is prolonged with increasing $U_{0}$. It was further identified from the Damköhler number and transport budget analyses that the deflagration mode of combustion is predominant for the RCCI combustion with mixing layer, except the end-gas auto-ignition. From the CEMA, it was verified that at the firststage ignition, low-temperature chemistry represented by the isomerization of $\mathrm{RO}_{2}$, chain branching reactions of $\mathrm{KOOH}$, and $\mathrm{H}$-atom abstraction of $n$-heptane is predominant. At the onset of the main stage combustion, the conversion reaction of $\mathrm{CO}$ to $\mathrm{CO}_{2}$ and hydrogen chemistry including $\mathrm{R} 1, \mathrm{R} 9$, and $\mathrm{R} 13$ are identified as the most important reactions for the combustion while temperature, $\mathrm{CO}$, and $\mathrm{OH}$ are the most important variables to the ignition process. These results suggest that both the excessive PRR and the ignition timing can be controlled not only by the degree of temperature, composition, and reactivity fluctuations in fuel/air charge but also by carefully-designed flow configurations to induce appropriate 
mixing layers between high reactivity fuel jet and low reactivity fuel/air charge.

\section{Acknowledgements}

This research was supported by Basic Science Research Program through the National Research Foundation of Korea (NRF) funded by the Ministry of Science and ICT (NRF2018R1A2A2A05018901). This research used the resources of the KAUST Supercomputing Laboratory and the UNIST Supercomputing Center.

\section{Reference}

[1] J. E. Dec, Advanced compression-ignition engines-understanding the in-cylinder processes, Proc. Combust. Inst. 32 (2009) 2727-2742.

[2] M. Yao, Z. Zheng, H. Liu, Progress and recent trends in homogeneous charge compression ignition (HCCI) engines, Prog. Energy Combust. Sci. 35 (2009) 398-437.

[3] J. E. Dec, Advanced Compression-Ignition Combustion for High Efficiency and Ultra-Low NOx and Soot, John Wiley \& Sons, Ltd, 2014.

[4] J. E. Dec, W. Hwang, Characterizing the development of thermal stratification in an HCCI engine using planar-imaging thermometry, SAE Trans. paper (2009) 2009-01-0650.

[5] R. D. Reitz, G. Duraisamy, Review of high efficiency and clean reactivity controlled compression ignition (RCCI) combustion in internal combustion engines, Prog. Energy Combust. Sci. 46 (2015) 12-71.

[6] S. L. Kokjohn, R. M. Hanson, D. A. Splitter, R. D. Reitz, Fuel reactivity controlled compression ignition (RCCI): A pathway to controlled high-efficiency clean combustion, Int. J. Engine Res. 12 (2011) 209226.

[7] S. L. Kokjohn, M. P. B. Musculus, R. D. Reitz, Evaluating temperature and fuel stratification for heat-release rate control in a reactivity-controlled compression-ignition engine using optical diagnostics and chemical kinetics modeling, Combust. Flame 162 (2015) 2729-2742.

[8] C. S. Yoo, T. Lu, J. H. Chen, C. K. Law, Direct numerical simulations of ignition of a lean $n$-heptane/air mixture with temperature inhomogeneities at constant volume: Parametric study, Combust. Flame 158 (2011) 1727-1741.

[9] C. S. Yoo, Z. Luo, T. Lu, H. Kim, J. H. Chen, A DNS study of ignition characteristics of a lean iso-heptane/air mixture under HCCI and SACI conditions, Proc. Combust. Inst. 34 (2013) 2985-2993.

[10] M. B. Luong, Z. Luo, T. Lu, S. H. Chung, C. S. Yoo, Direct numerical simulations of the ignition of lean primary reference fuel/air mixtures with temperature inhomogeneities, Combust. Flame 160 (2013) 2038-2047. 
[11] M. B. Luong, T. Lu, S. H. Chung, C. S. Yoo, Direct numerical simulations of the ignition of a lean biodiesel/air mixture with temperature and composition inhomogeneities at high pressure and intermediate temperature, Combust. Flame 161 (2014) 2878-2889.

[12] M. B. Luong, G. H. Yu, T. Lu, S. H. Chung, C. S. Yoo, Direct numerical simulations of ignition of a lean $n$-heptane/air mixture with temperature and composition inhomogeneities relevant to HCCI and SCCI combustion, Combust. Flame 162 (2015) 4566-4585.

[13] A. Bhagatwala, R. Sankaran, S. Kokjohn, J. H. Chen, Numerical investigation of spontaneous flame propagation under RCCI conditions, Combust. Flame 162 (2015) 3412-3426.

[14] M. B. Luong, R. Sankaran, G. H. Yu, S. H. Chung, C. S. Yoo, On the effect of injection timing on the ignition of lean PRF/air/EGR mixtures under direct dual fuel stratification conditions, Combust. Flame 183 (2017) 309-321.

[15] M. B. Luong, G. H. Yu, S. H. Chung, C. S. Yoo, Ignition of a lean PRF/air mixture under RCCI/SCCI conditions: Chemical aspects, Proc. Combust. Inst. 36 (2017) 3587-3596.

[16] M. B. Luong, G. H. Yu, S. H. Chung, C. S. Yoo, Ignition of a lean PRF/air mixture under RCCI/SCCI conditions: A comparative DNS study, Proc. Combust. Inst. 36 (2017) 3623-3631.

[17] H. G. Im, J. H. Chen, C. K. Law, Ignition of hydrogen-air mixing layer in turbulent flows, Proc. Combust. Inst. 27 (1998) 1047-1056.

[18] E. Mastorakos, T. A. Baritaud, T. J. Poinsot, Numerical simulations of autoignition in turbulent mixing flows, Combust. Flame 109 (1997) 198-223.

[19] E. Mastorakos, Ignition of turbulent non-premixed flames, Prog. Energy Combust. Sci. 35 (2009) 57-97.

[20] P. Schroll, A. P. Wandel, R. S. Cant, E. Mastorakos, Direct numerical simulations of autoignition in turbulent two-phase flows, Proc. Combust. Inst. 32 (2009) 2275-2282.

[21] G. Borghesi, E. Mastorakos, R. S. Cant, Complex chemistry DNS of $n$-heptane spray autoignition at high pressure and intermediate temperature conditions, Combust. Flame 160 (2013) 1254-1275.

[22] E. Demosthenous, G. Borghesi, E. Mastorakos, R. S. Cant, Direct numerical simulations of premixed methane flame initiation by pilot $n$-heptane spray autoignition, Combust. Flame 163 (2016) 122-137.

[23] T. Jin, K. H. Luo, X. Wang, K. Luo, J. Fan, Dynamsics of triple-flames in ignition of turbulent dual fuel mixture: A direct numerical simulation study, Proc. Combust. Inst. 37 (2019) 4625-4633.

[24] A. Krisman, E. R. Hawkes, M. Talei, A. Bhagatwala, J. H. Chen, Characterisation of two-stage ignition in diesel engine-relevant thermochemical conditions using direct numerical simulation, Combust. Flame 172 (2016) 326-341.

[25] A. Krisman, E. R. Hawkes, M. Talei, A. Bhagatwala, J. H. Chen, A direct numerical simulation of cool-flame affected autoignition in diesel engine-relevant conditions, Proc. Combust. Inst. 36 (2017) $3567-3575$. 
[26] G. Borghesi, A. Krisman, T. Lu, J. H. Chen, Direct numerical simulation of a temporally evolving air/n-dodecane jet at low-temperature diesel-relevant conditions, Combust. Flame 195 (2018) 183-202.

[27] S. Imtenan, S. M. A. Rahman, H. H. Masjuki, M. Varman, M. A. Kalam, Effect of dynamic injection pressure on performance, emission and combustion characteristics of a compression ignition engine, Renew. Sust. Energ. Rev. 52 (2015) 1205-1211.

[28] I. Celikten, An experimental investigation of the effect of the injection pressure on engine performance and exhaust emission in indirect injection diesel engines, Appl. Therm. Eng. 23 (2003) 2051-2060.

[29] R. A. Bakar, S. Ismail, A. R. Ismail, Fuel injection pressure effect on performance of direct injection diesel engines based on experiment, Amer. J. Appl. Sci. 5 (2008) 197-202.

[30] T. Lu, C. S. Yoo, J. H. Chen, C. K. Law, Three-dimensional direct numerical simulation of a turbulent lifted hydrogen jet flame in heated coflow: A chemical explosive mode analysis, J. Fluid Mech. 652 (2010) 45-64.

[31] Z. Luo, C. S. Yoo, E. S. Richardson, R. Sankaran, J. H. Chen., Chemical explosive mode analysis for a turbulent lifted ethylene jet flame in highly-heated coflow, Combust. Flame 159 (2012) 265-274.

[32] R. Shan, C. S. Yoo, J. H. Chen, T. Lu, Computational diagnostics for $n$-heptane flames with chemical explosive mode analysis, Combust. Flame 159 (2012) 3119-3127.

[33] J. H. Chen, A. Choudhary, B. de Supinski, M. DeVries, E. R. Hawkes, S. Klasky, W. K. Liao, K. L. Ma, J. Mellor-Crummey, N. Podhorszki, R. Sankaran, S. Shende, C. S. Yoo, Terascale direct numerical simulations of turbulent combustion using S3D, Comput. Sci. Discov. 2 (2009) 015001.

[34] R. J. Kee, G. Dixon-Lewis, J. Warnatz, M. E. Coltrin, J. A. Miller, A fortran computer code package for the evaluation of gas-phase multicomponent transport properties, Tech. Rep. SAND86-8246, Sandia National Laboratories (1986).

[35] R. J. Kee, F. M. Rupley, E. Meeks, J. A. Miller, CHEMKIN-III: A fortran chemical kinetic package for the anaylsis of gas-phase chemical and plasma knietics, Tech. Rep. SAND96-8216, Sandia National Laboratories (1996).

[36] C. A. Kennedy, M. H. Carpenter, Several new numerical methods for compressible shear-layer simulations, Appl. Num. Math. 14 (1994) 397-433.

[37] C. A. Kennedy, M. H. Carpenter, R. M. Lewis, Low-storage, explicit Runge-Kutta schemes for the compressible Navier-Stokes equations, Appl. Num. Math. 35 (2000) 117-219.

[38] T. Lu, C. K. Law, C. S. Yoo, J. H. Chen, Dynamic stiffness removal for direct numerical simulations, Combust. Flame 156 (2009) 1542-1551.

[39] J. B. Heywood, Internal combustion engine fundamentals, Mcgraw-Hill, 1988.

[40] M. Wissink, R. D. Reitz, Direct dual fuel stratification, a path to combine the benefits of RCCI and PPC, SAE Int. J. Engines 8 (2015) 878-889. 
[41] Y. Wang, C. J. Rutland, Effects of temperature and equivalence ratio on the ignition of $n$-heptane fuel spray in turbulent flow, Proc. Combust. Inst. 30 (2005) 893-900.

[42] S. Kokjohn, R. Reitz, D. Splitter, M. Musculus, Investigation of fuel reactivity stratification for controlling PCI heat-release rates using high-speed chemiluminescence imaging and fuel tracer fluorescence, SAE paper (2012) 2012-01-0375.

[43] W. Hwang, J. E. Dec, M. Sjöberg, Fuel stratification for low-load HCCI combustion: Performance and fuel-PLIF measurements, SAE Trans. paper 116 (2007) 2007-01-4130.

[44] Q. Tang, H. Liu, M. Li, M. Yao, Z. Li, Study on ignition and flame development in gasoline partially premixed combustion using multiple optical diagnostics, Combust. Flame 177 (2017) 98-108.

[45] S. Saxena, I. D. Bedoya, Fundamental phenomena affecting low temperature combustion and HCCI engines, high load limits and strategies for extending these limits, Prog. Energy Combust. Sci. 39 (2013) $457-488$.

[46] J. H. Chen, E. R. Hawkes, R. Sankaran, S. D. Mason, H. G. Im, Direct numerical simulation of ignition front propagation in a constant volume with temperature inhomogeneities: I. Fundamental analysis and diagnostics, Combust. Flame 145 (2006) 128-144.

[47] S. O. Kim, M. B. Luong, J. H. Chen, C. S. Yoo, A DNS study of the ignition of lean PRF/air mixtures with temperature inhomogeneities under high pressure and intermediate temperature, Combust. Flame 162 (2015) 717-726.

[48] T. Passot, A. Pouquet, Numerical simulation of compressible homogeneous flows in the turbulent regime, J. Fluid Mech. 118 (1987) 441-466.

[49] E. R. Hawkes, R. Sankaran, P. Pébay, J. H. Chen, Direct numerical simulation of ignition front propagation in a constant volume with temperature inhomogeneities: II. Parametric study, Combust. Flame 145 (2006) 145-159.

[50] A. Hultqvist, M. Christenson, B. Johansson, M. Richter, J. Nygren, J. Hult, M. Alden, The HCCI combustion process in a single cycle-speed fuel tracer LIF and chemiluminescence imaging, SAE paper (2002) 2002-01-0424.

[51] R. Yu, X.-S. Bai, Direct numerical simulation of lean hydrogen/air auto-ignition in a constant volume enclosure, Combust. Flame 160 (2013) 1706-1716.

[52] G. Bansal, A. Mascarenhas, J. H. Chen, Direct numerical simulations of autoignition in stratified dimethyl-ether (DME)/air turbulent mixtures, Combust. Flame 162 (2015) 688-702.

[53] A. Bhagatwala, J. H. Chen, T. Lu, Direct numerical simulations of HCCI/SACI with ethanol, Combust. Flame 161 (2014) 1826-1841.

[54] D. O. Lignell, J. H. Chen, P. J. Smith, T. Lu, C. K. Law, The effect of flame structure on soot formation and transport in turbulent nonpremixed flames using direct numerical simulation, Combust. Flame 151 
(2007) 2-28.

[55] D. O. Lignell, J. H. Chen, P. J. Smith, Three-dimensional direct numerical simulation of soot formation and transport in a temporally evolving nonpremixed ethylene jet flame, Combust. Flame 155 (2008) $316-333$.

[56] C. S. Yoo, E. S. Richardson, R. Sankaran, J. H. Chen, A DNS study on the stabilization mechanism of a turbulent lifted ethylene jet flame in highly-heated coflow, Proc. Combust. Inst. 33 (2011) 1619-1627.

[57] T. Echekki, J. H. Chen, Direct numerical simulation of autoignition in non-homogeneous hydrogen-air mixtures, Combust. Flame 134 (2003) 169-191.

[58] C. S. Yoo, R. Sankaran, J. H. Chen, Three-dimensional direct numerical simulation of a turbulent lifted hydrogen jet flame in heated coflow: Flame stabilization and structure, J. Fluid Mech. 640 (2009) 453-481.

[59] K. S. Jung, S. O. Kim, T. Lu, S. H. Chung, B. J. Lee, C. S. Yoo, differential diffusion effect on the stabilization characteristics of autoignited laminar lifted methane/hydrogen jet flames in heated coflow air, Combust. Flame 198 (2018) 305-319.

[60] F. Zhang, H. F. Liu, R. Yu, M. Yao, X. S. Bai, Direct numerical simulation of $\mathrm{H}_{2} /$ air combustion with composition stratification in a constant volume enclosure relevant to HCCI engines, Int. J. Hydrog. Energy 41 (2016) 13758-13770.

[61] H. S. Bak, C. S. Yoo, Flame instabilities and flame cell dynamics in opposed nonpremixed tubular flames with radiative heat loss, Combust. Flame 194 (2018) 322-333. 
Table 1: Engine specifications [40] and key parameters for DNSs. RPM and ${ }^{\circ} \mathrm{CA}$ ATDC denote revolutions per minute and degrees of crank-angle after top dead center, respectively.

\begin{tabular}{ll}
\hline Relevant engine parameters & \\
\hline Ratio of connecting-rod length to crank radius & 3.17 \\
Compression ratio & $14.88: 1$ \\
Intake pressure & $1.00(\mathrm{~atm})$ \\
Engine speed & $1300(\mathrm{RPM})$ \\
\hline Parameters at initial conditions & \\
\hline Initial crack angle & $-25\left({ }^{\circ} \mathrm{CA}\right.$ ATDC) \\
Initial mean temperature, $T_{0}$ & $720(\mathrm{~K})$ \\
Initial mean iso-octane stream temperature, $T_{\text {oct }}$ & $740(\mathrm{~K})$ \\
Initial mean $n$-heptane jet temperature, $T_{h e p}$ & $650(\mathrm{~K})$ \\
Initial temperature fluctuation, $T_{h e p}^{\prime}$ & $20(\mathrm{~K})$ \\
Initial mean pressure, $P_{0}$ & $18.2(\mathrm{~atm})$ \\
Initial mean equivalence ratio, $\phi_{0}$ & 0.45 \\
Initial mean PRF number, $\mathrm{PRF}_{0}$ & $\mathrm{PRF} 50$ \\
\hline
\end{tabular}

Table 2: Physical parameters of 2-D DNS cases. The subscripts 'oct' and 'hep' represent the iso-octane/air stream and $n$-heptane jet, respectively.

\begin{tabular}{crccccccccc}
\hline Case & $U_{0}(\mathrm{~m} / \mathrm{s})$ & $\phi_{0}$ & $\phi_{\text {oct }}$ & $\phi_{\text {hep }}$ & $\phi_{\text {hep }}^{\prime}$ & $T_{\text {oct }}(\mathrm{K})$ & $T_{\text {hep }}(\mathrm{K})$ & $T_{\text {hep }}^{\prime}(\mathrm{K})$ & $l_{e}(\mathrm{~mm})$ & $u^{\prime}(\mathrm{m} / \mathrm{s})$ \\
\hline 1 & 0.0 & 0.45 & 0.23 & 1.29 & 0.38 & 740 & 650 & 20 & 1.2 & 0.4 \\
2 & 5.0 & 0.45 & 0.23 & 1.29 & 0.38 & 740 & 650 & 20 & 1.2 & 0.4 \\
3 & 10.0 & 0.45 & 0.23 & 1.29 & 0.38 & 740 & 650 & 20 & 1.2 & 0.4 \\
\hline
\end{tabular}




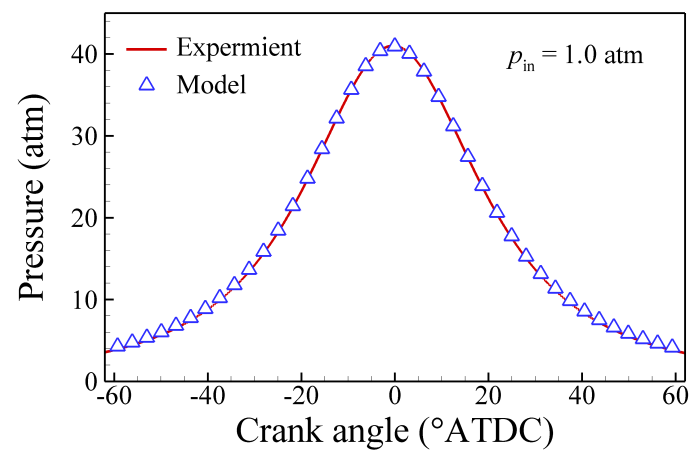

Figure 1: Experimental and modeled motored-pressure history as a function of crank angle degrees $\left({ }^{\circ} \mathrm{CA}\right)$. Experimental motored-pressure trace is taken from experimental by Wissink and Reitz [40] operating at $1300 \mathrm{RPM}$ and $P_{\text {in }}=1.0 \mathrm{~atm}$

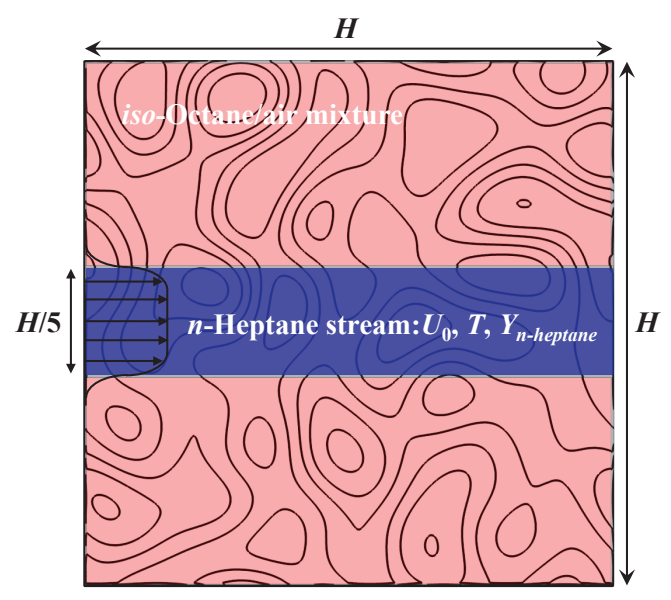

Figure 2: Schematic of the computational domain. 
(a)
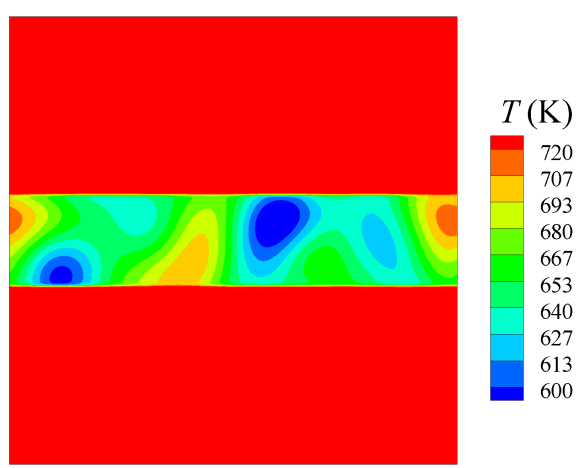

(b)

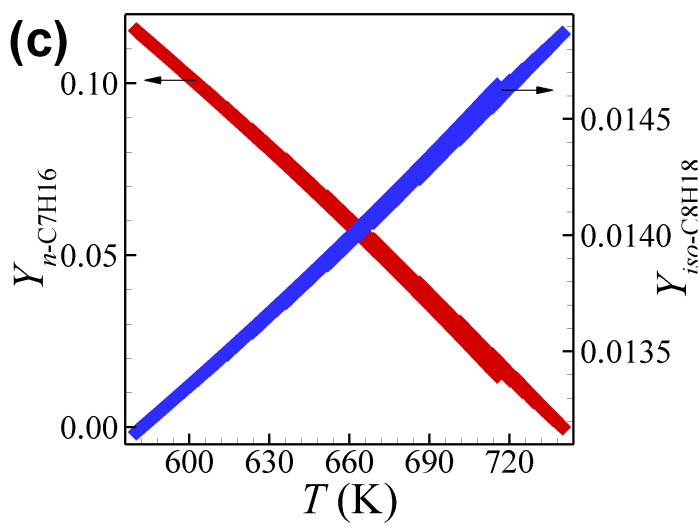

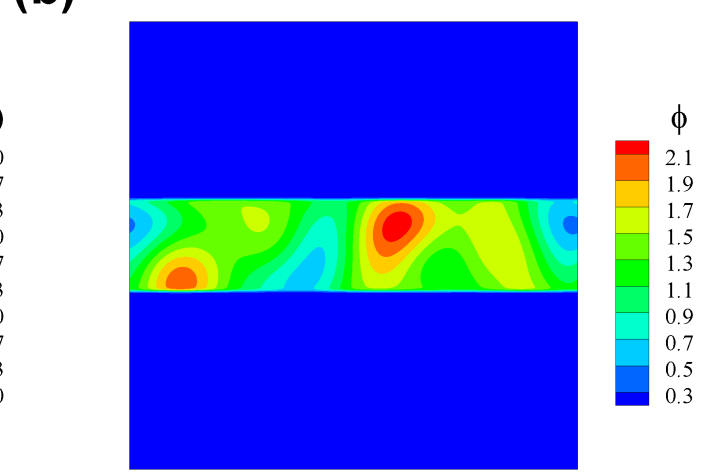

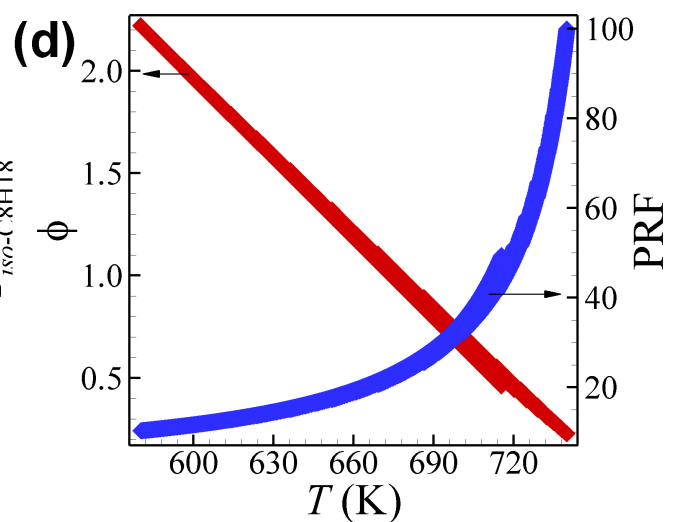

Figure 3: Initial field of (a) $T$, and (b) $\phi$, and initial distribution of (c) the mass fraction of $T-Y_{\text {hep }}$ and $T-Y_{\text {oct }}$, and (d) $T-\phi$, and $T-P R F$ for Cases 1-3 

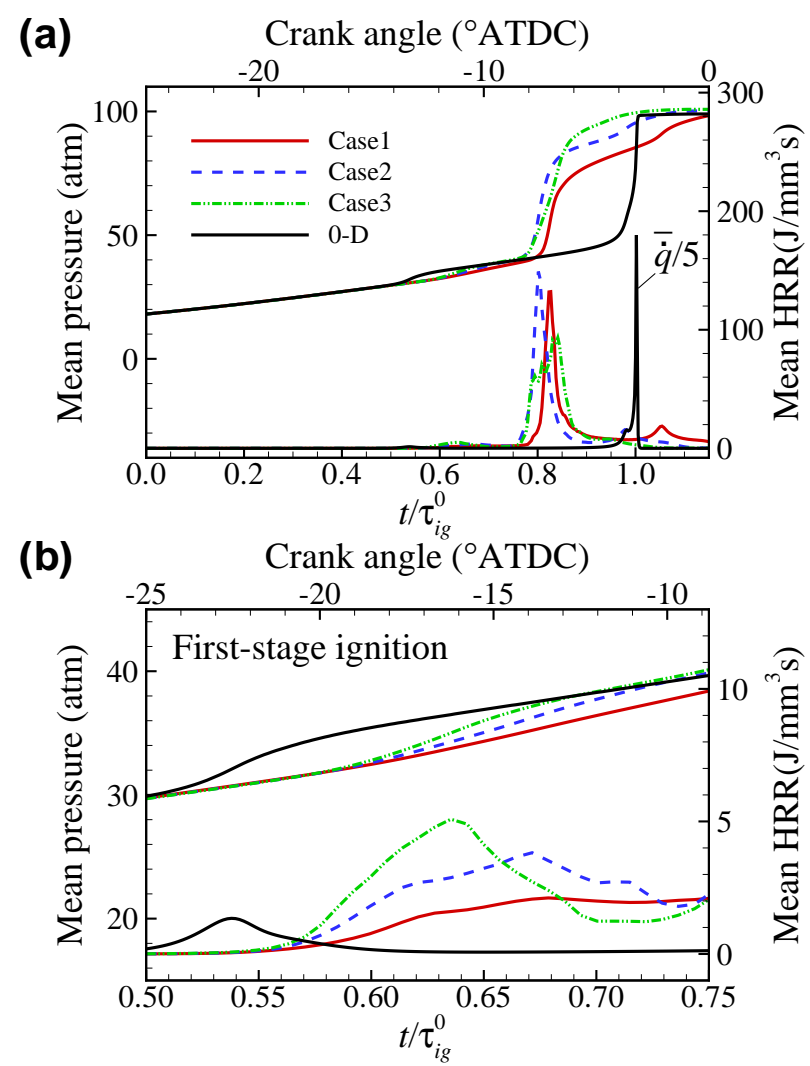

Figure 4: Temporal evolutions of the mean pressure and the mean heat release rate for Cases 1-3 together with those of 0-D ignition of PRF50/air mixture during (a) the whole combustion process and (b) only the first-stage ignition. 

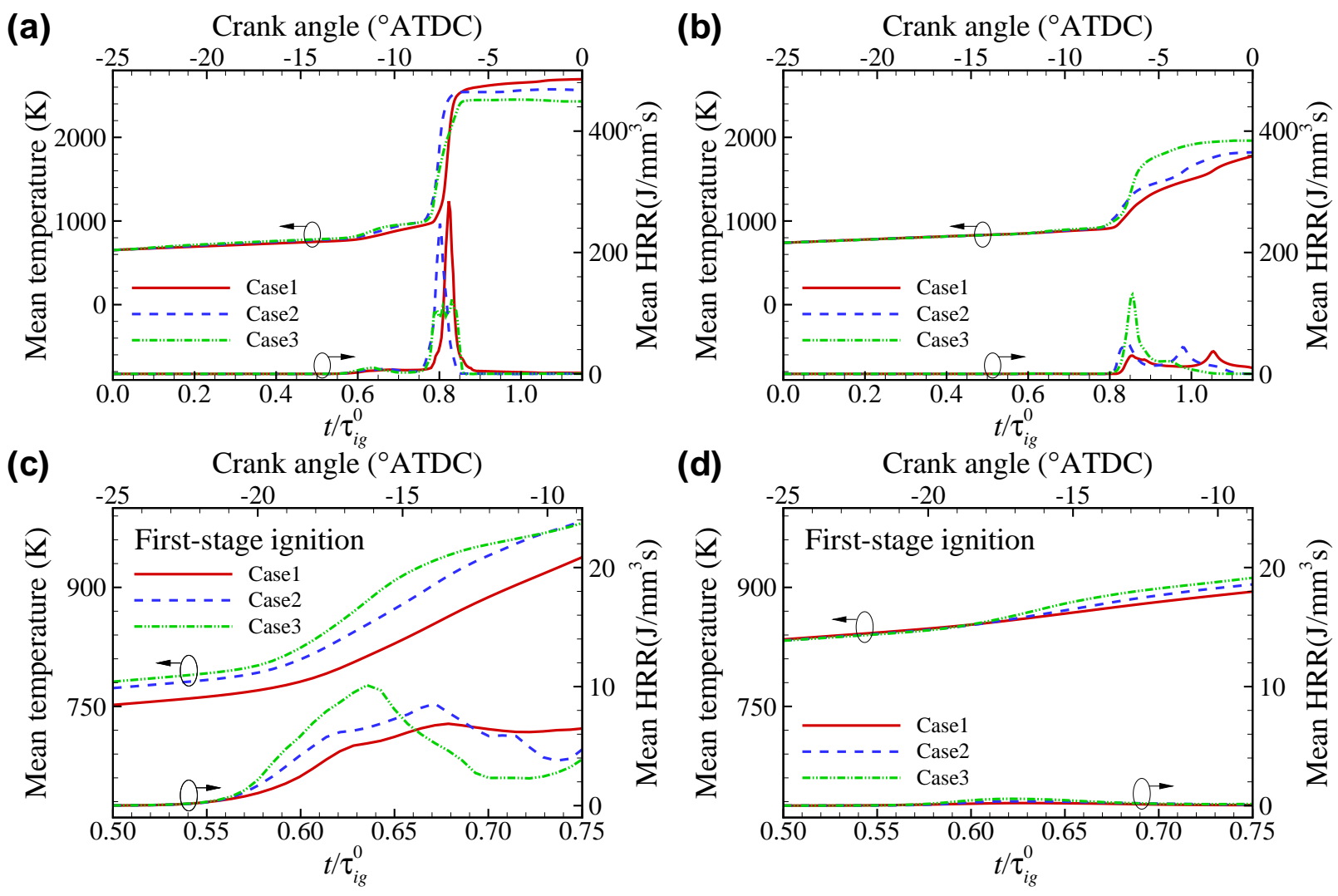

Figure 5: Temporal evolutions of the mean temperature and the mean heat release rate in the $n$-heptane jet (left) and the iso-octane/air stream (right) for Cases 1-3 during the whole combustion process (top) and only the first-stage ignition (bottom). 


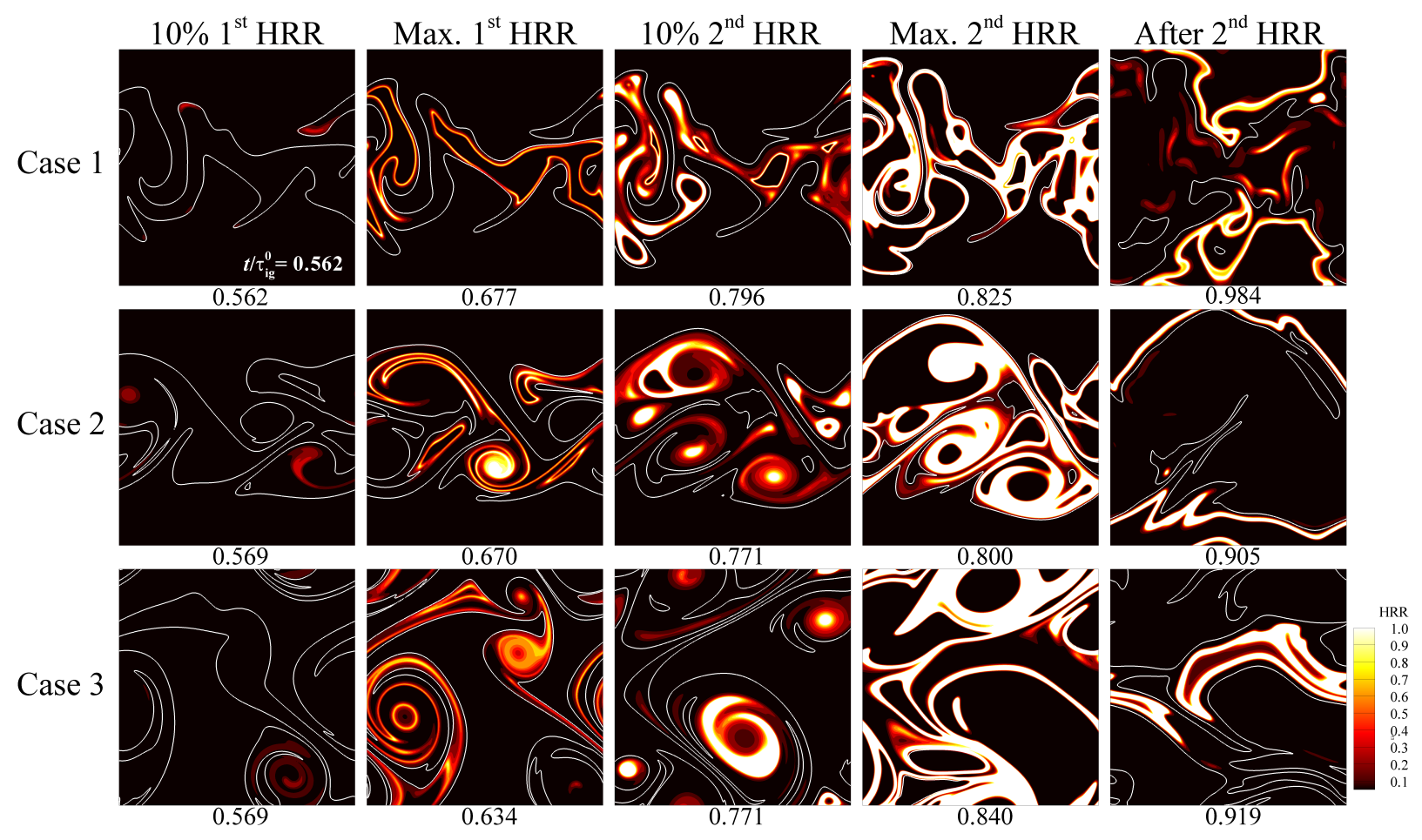

Figure 6: Instantaneous snapshots of HRR fields at several different times for Cases 1-3. 

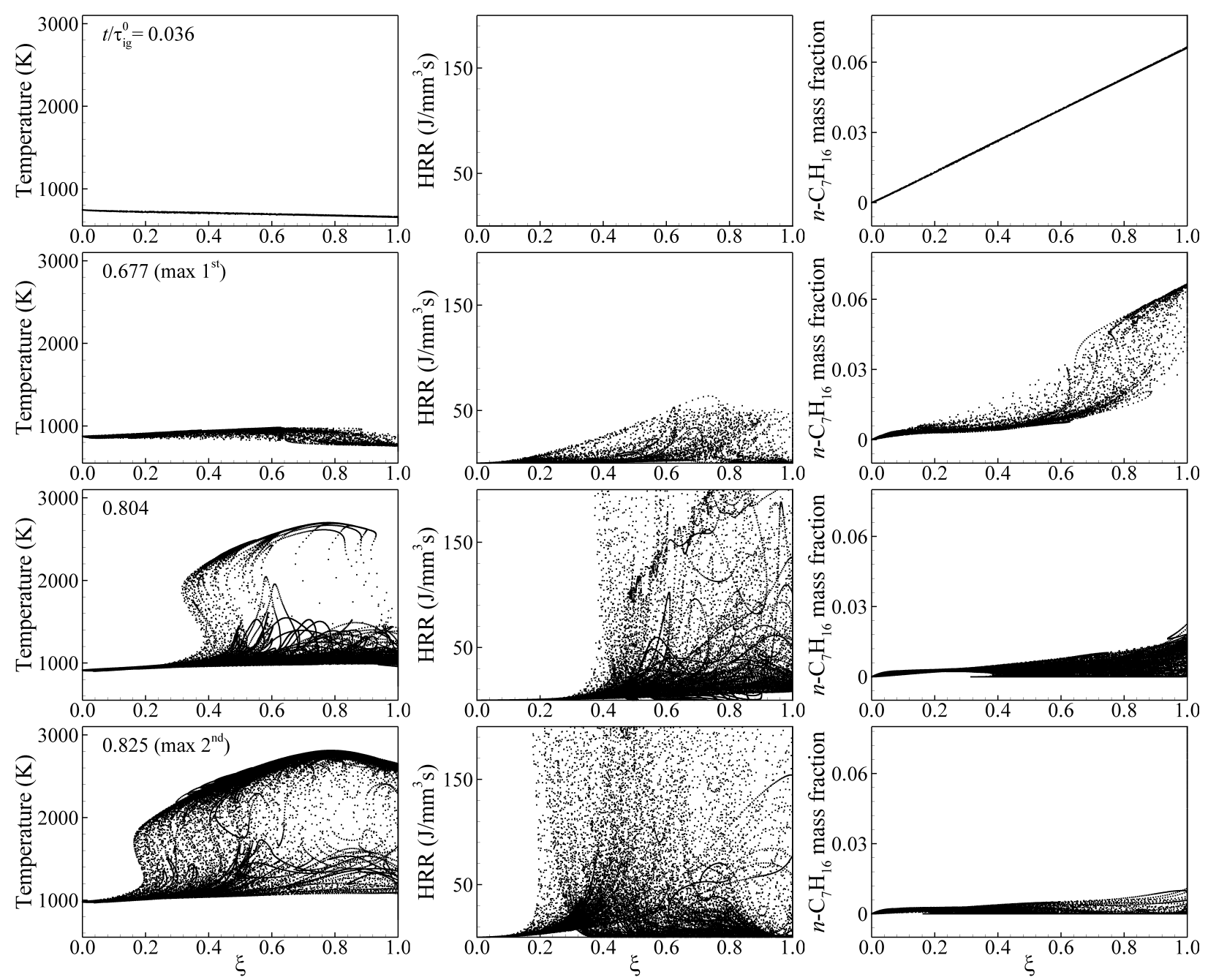

Figure 7: Scatter plots of temperature (first column), heat release rate (second column), and $n$-heptane mass fraction (third column) as a function of the mixture fraction at several instants for Case 1. 

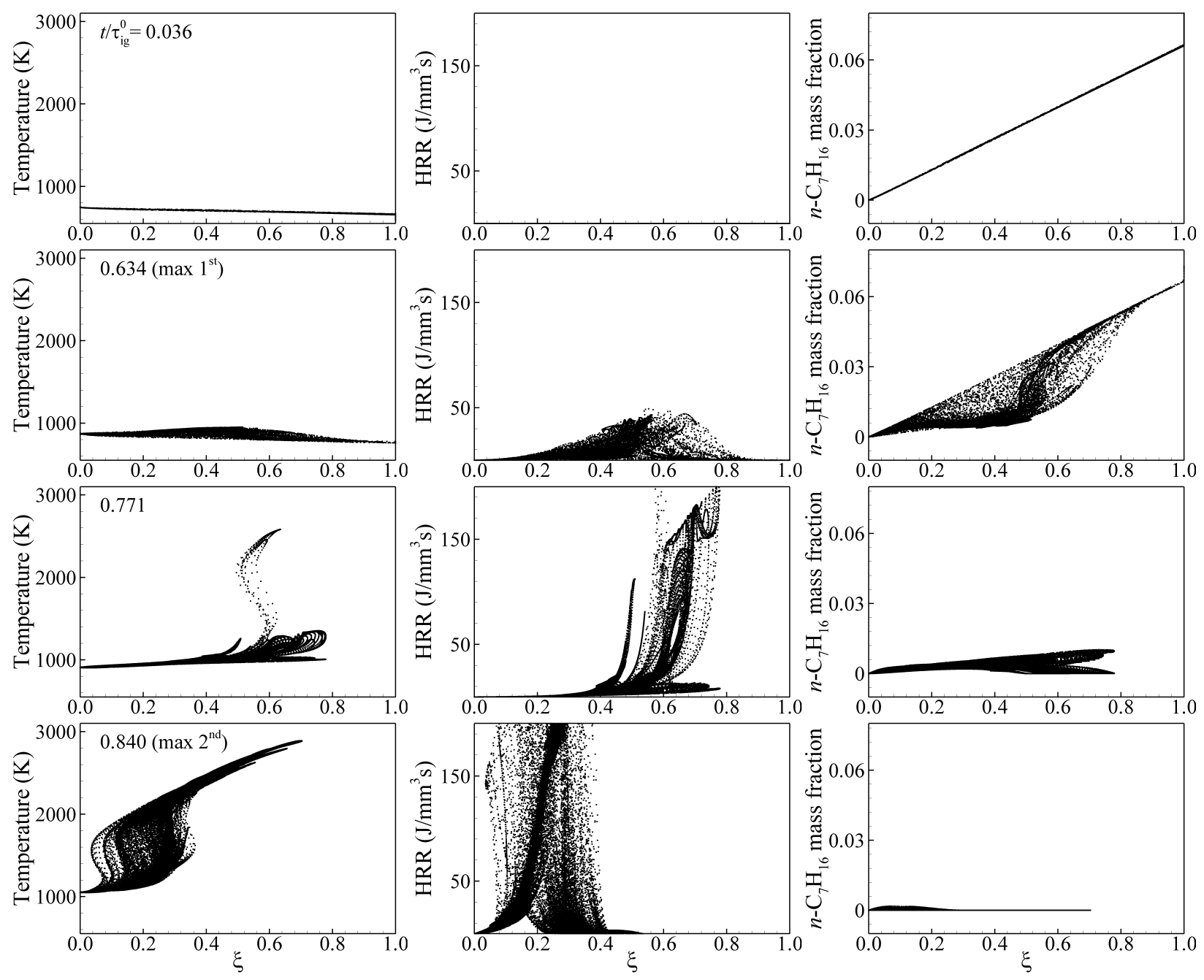

Figure 8: Scatter plots of temperature (first column), heat release rate (second column), and $n$-heptane mass fraction (third column) as a function of the mixture fraction at several instants for Case 3. 

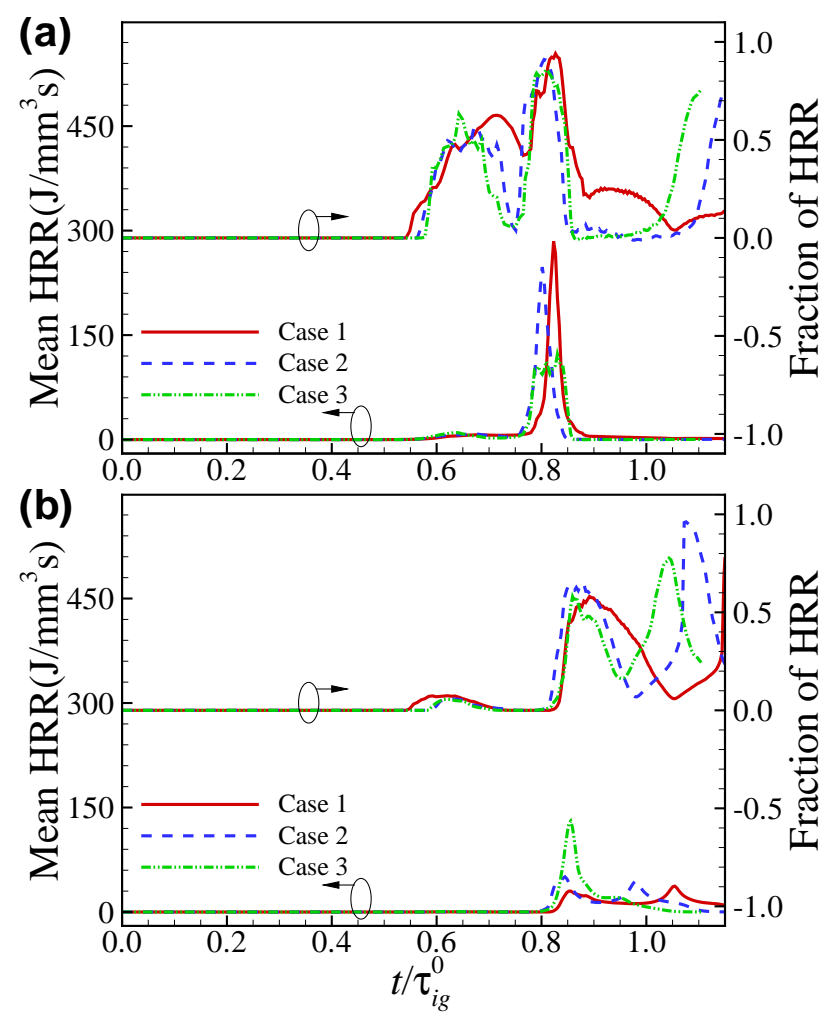

Figure 9: Temporal evolutions of the fraction of heat release rate from the deflagration mode and the mean heat release rate in (a) the $n$-heptane jet and (b) the iso-octane/air stream for Cases 1-3.

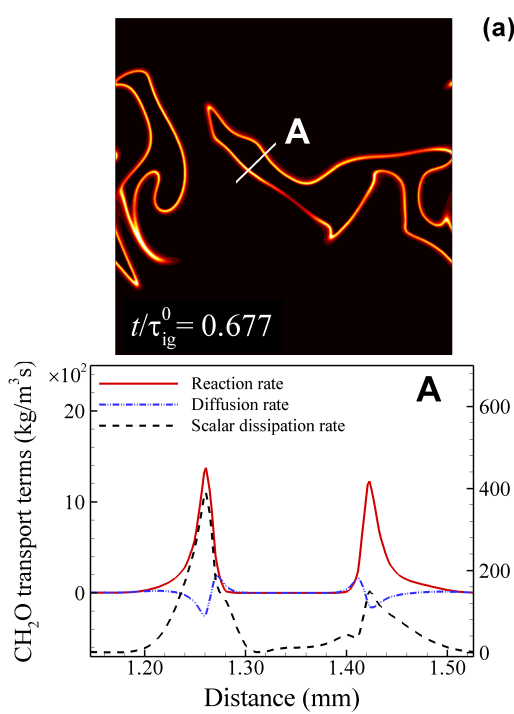

(a)

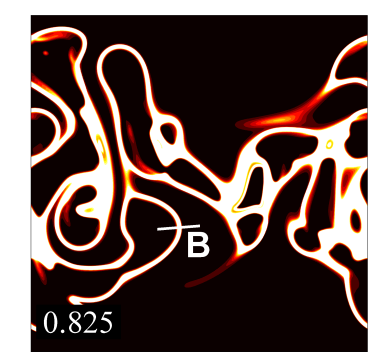

(b)
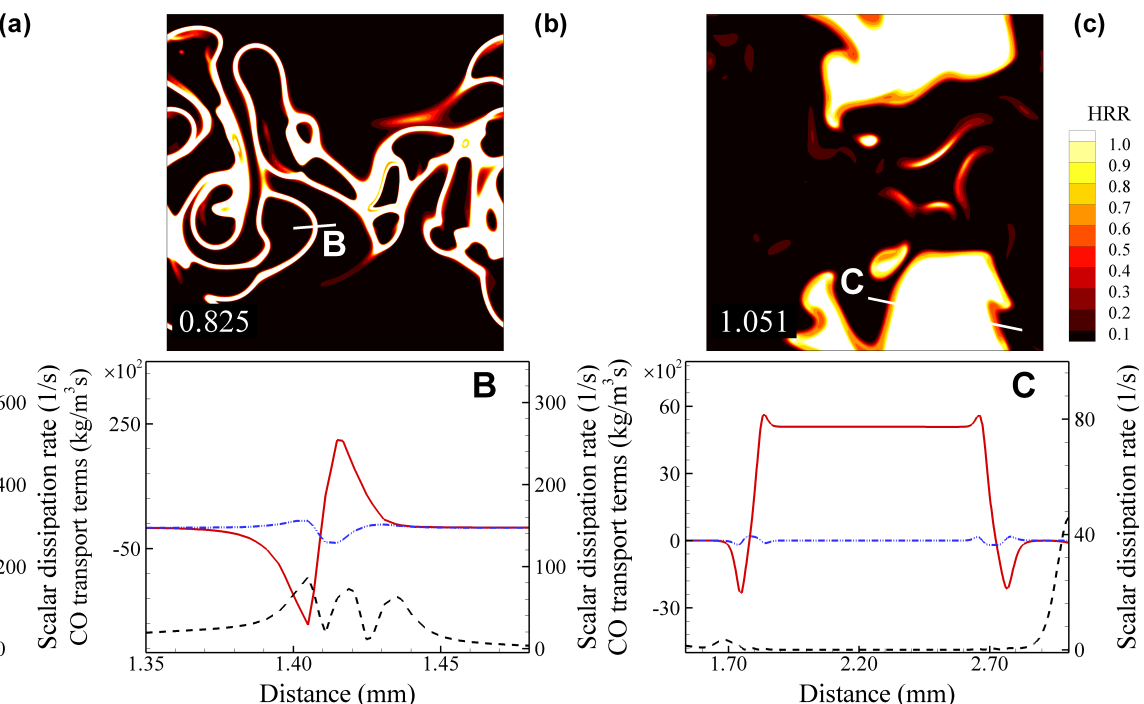

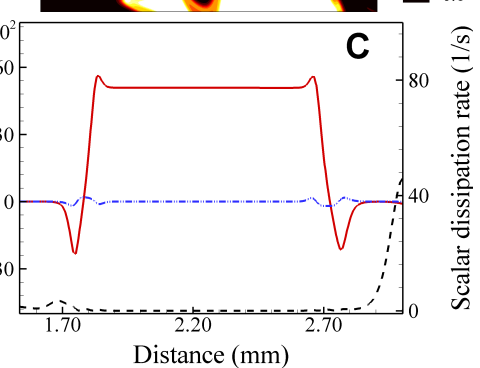

Figure 10: (a) Isocontours of the normalized HRR for Case 1 at the first-stage ignition, (b) the second-stage ignition, and (c) the third-stage ignition together with the profiles of reaction and diffusion terms of $\mathrm{CH}_{2} \mathrm{O}$ and $\mathrm{CO}$ along each cut line of $\mathrm{A}, \mathrm{B}$, and $\mathrm{C}$. 

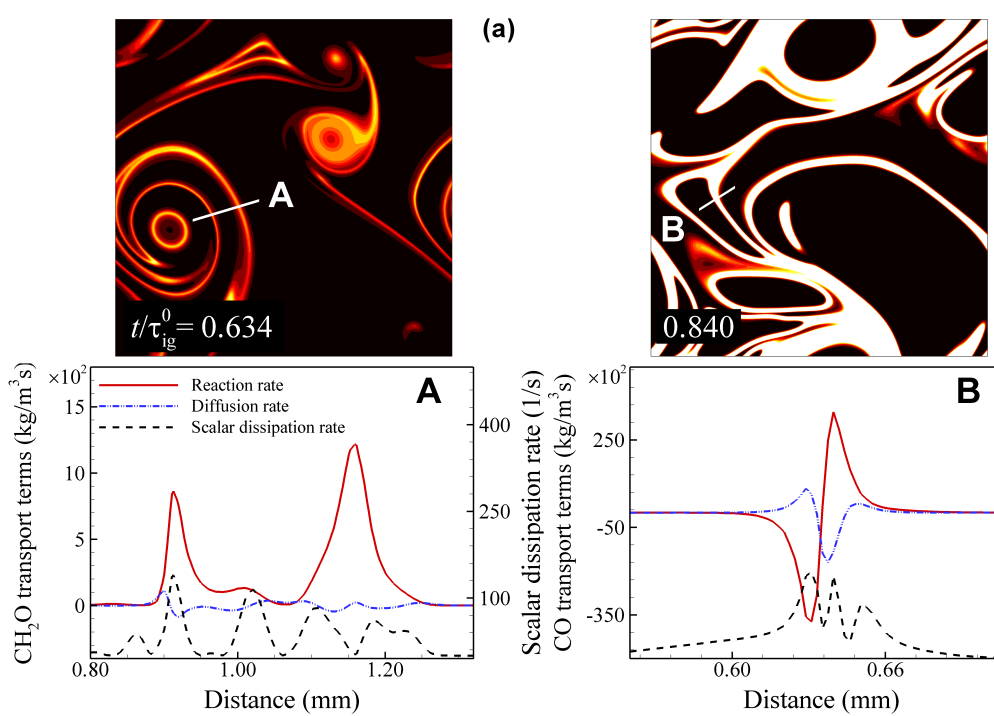

(b)
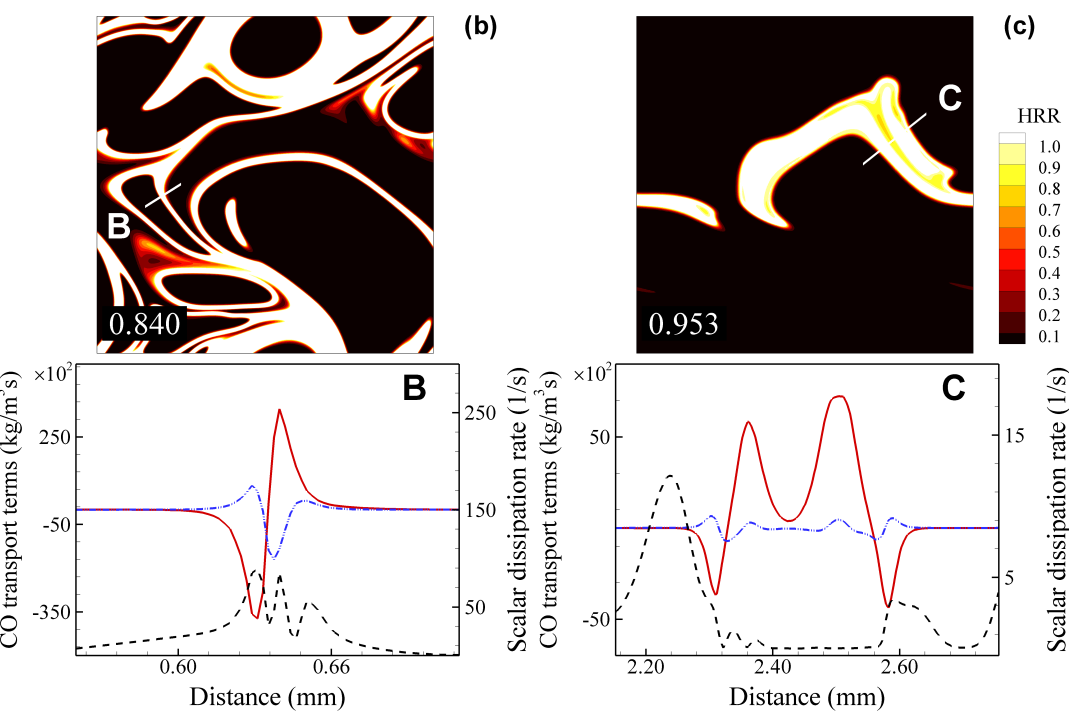

Figure 11: (a) Isocontours of the normalized heat release rate of Case 3 at the first-stage ignition, (b) the second-stage ignition, and (c) the third-stage ignition together with the profiles of reaction and diffusion terms of $\mathrm{CH}_{2} \mathrm{O}$ and $\mathrm{CO}$ along each cut line of $\mathrm{A}, \mathrm{B}$, and $\mathrm{C}$.
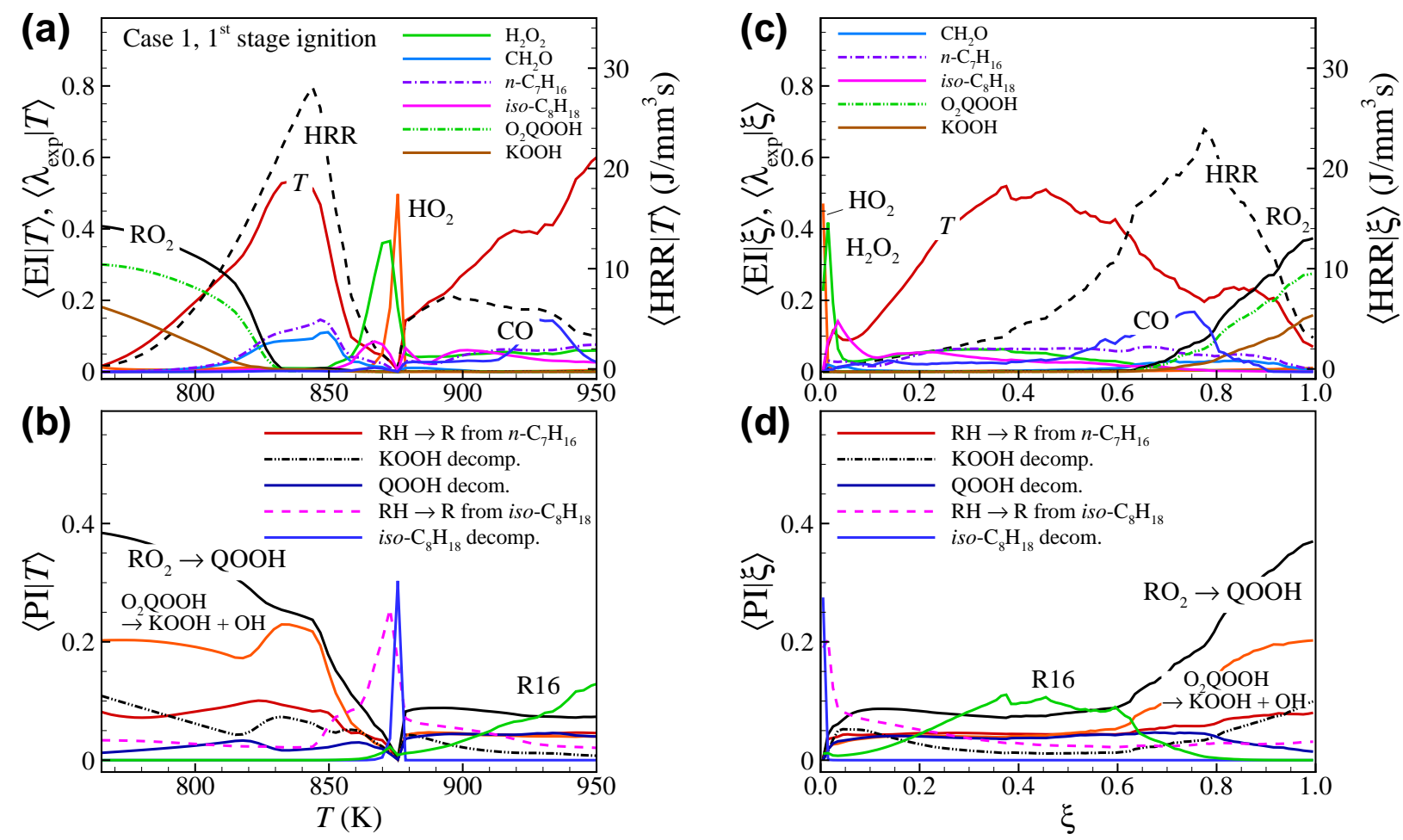

Figure 12: Conditional means of HRR, EI, and PI given temperature (left column) and mixture fraction (right column) for Case 1 at the first-stage ignition, $t / \tau_{i g}^{0}=0.667$. 

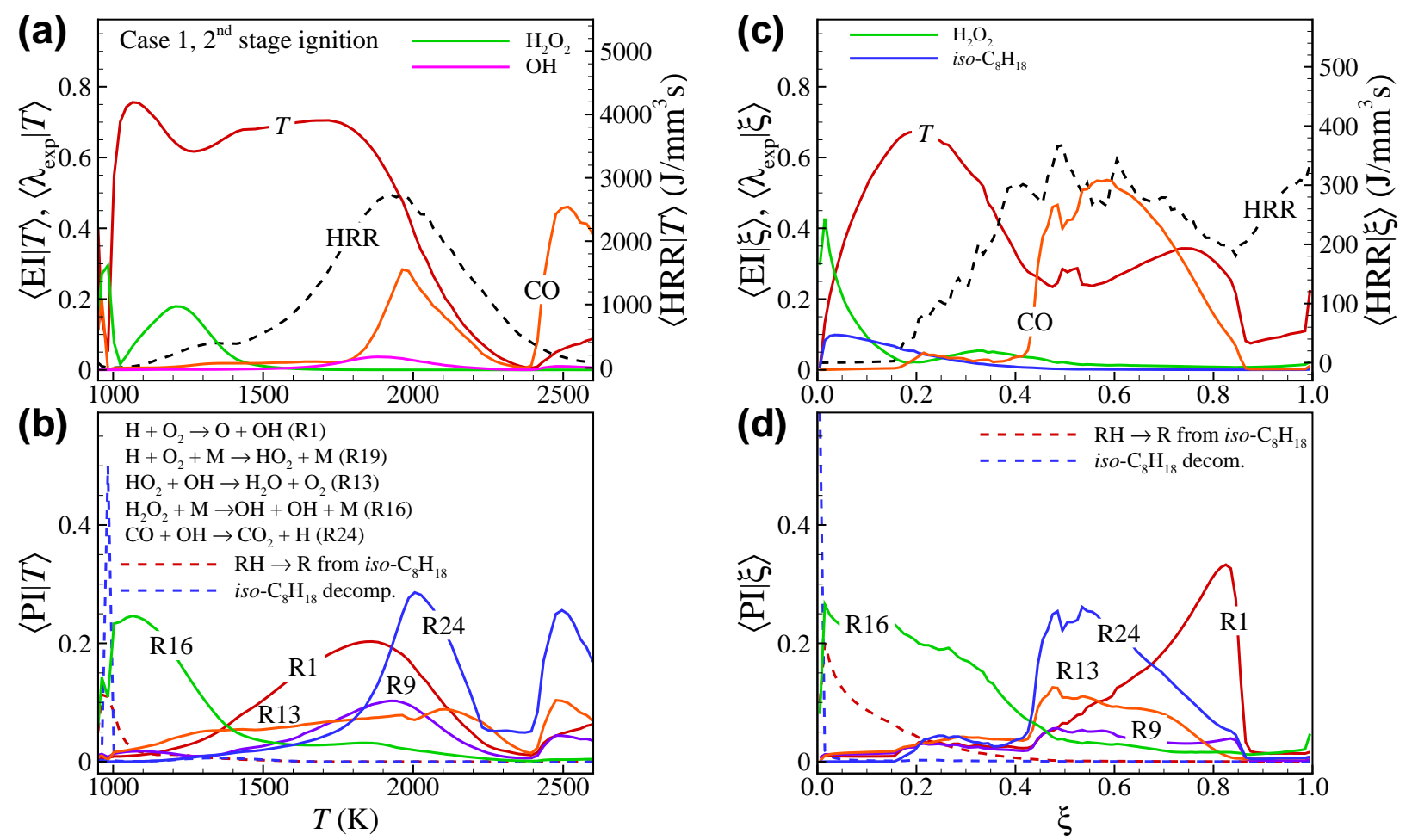

Figure 13: Conditional mean of HRR, EI, and PI given temperature (left column) and mixture fraction (right column) for Case 1 at the second-stage ignition, $t / \tau_{i g}^{0}=0.825$. 

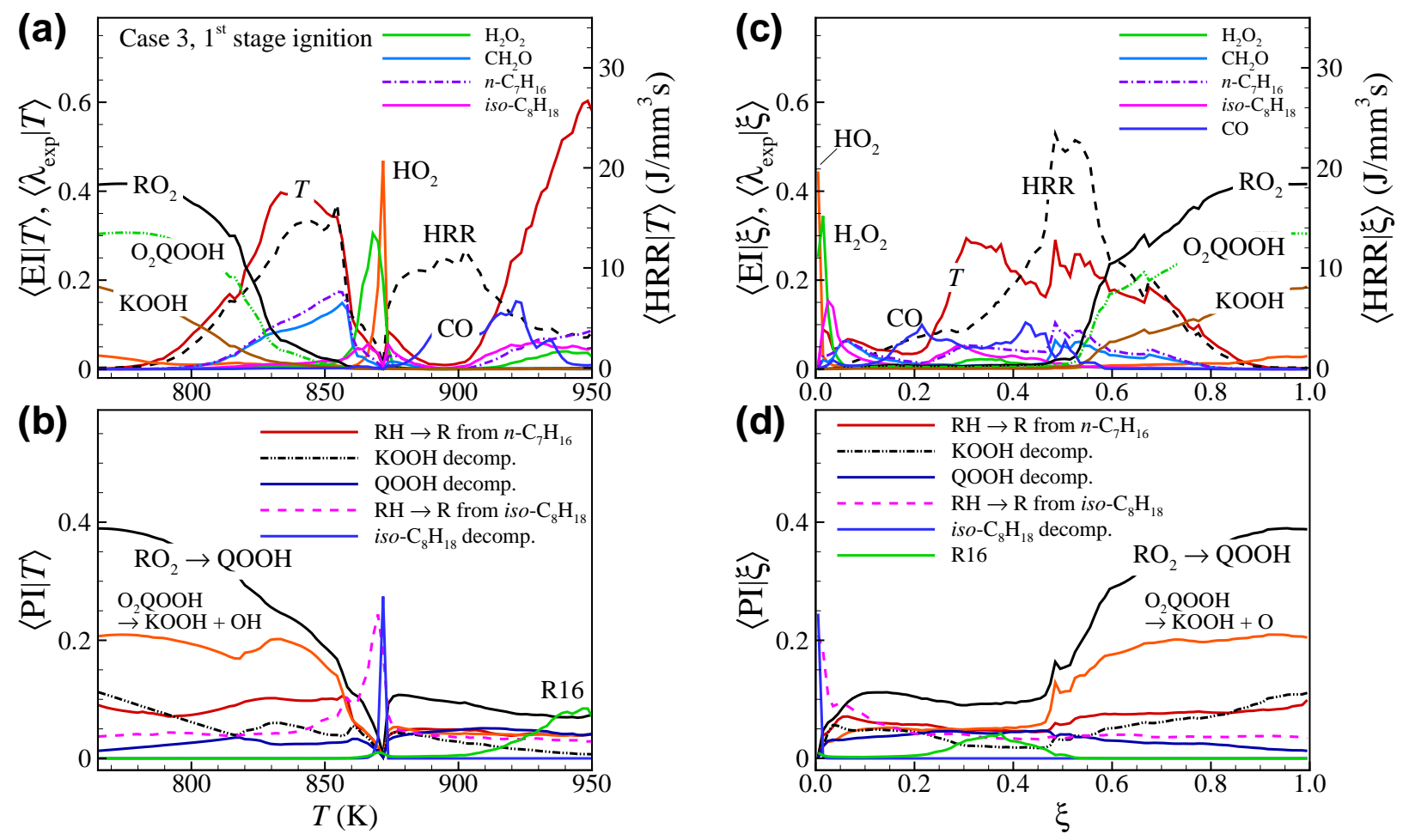

Figure 14: Conditional mean of HRR, EI of critical variables, and PI of critical reactions given temperature (left column) and mixture fraction (right column) for Case 3 at the first-stage ignition, $t / \tau_{i g}^{0}=0.635$. 

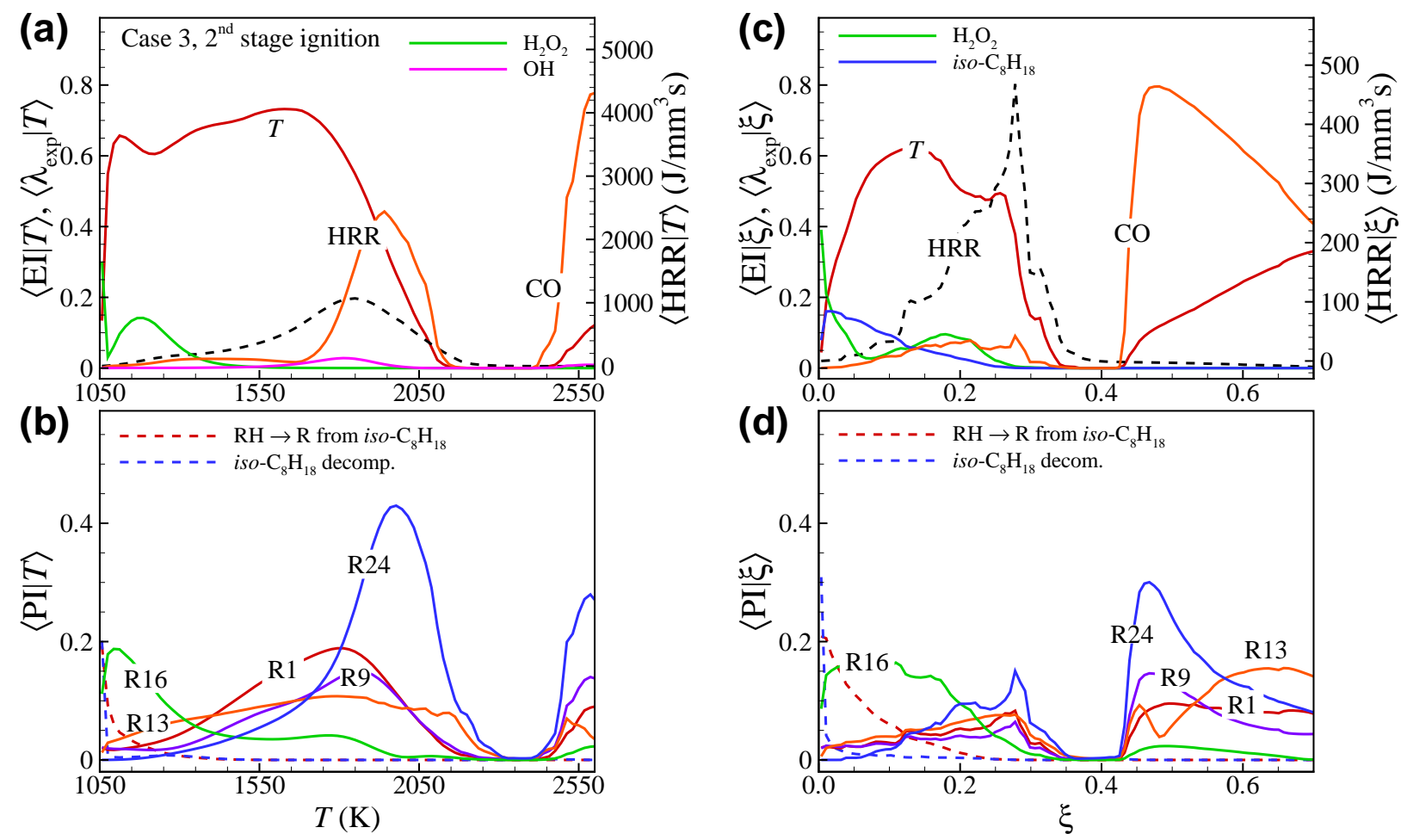

Figure 15: Conditional mean of HRR, EI of critical variables, and PI of critical reactions given temperature (left column) and mixture fraction (right column) for Case 3 at the second-stage ignition, $t / \tau_{i g}^{0}=0.841$. 